\title{
Mercado de trabalho, salário mínimo e estrutura tributária: impactos sobre o perfil distributivo brasileiro em perspectiva histórica
}

\begin{abstract}
Resumo
Este artigo pretende destacar aspectos históricos relacionados à evolução do salário mínimo, à dinâmica do mercado de trabalho e às transformações na estrutura tributária desde meados do século $X X$ e, de seus efeitos sobre indicadores de evolução do perfil de distribuição de renda no Brasil. Na primeira parte, é analisada a evolução do índice de Gini de 1960 até o presente, destacando o papel desempenhado pelo salário mínimo na determinação dos movimentos no perfil distributivo. Na segunda parte, é feita uma retrospectiva histórica da montagem da atual estrutura tributária, destacando-se a reforma tributária de 1967, que consolida as bases sobre as quais se assenta a estrutura tributária até hoje. Dessa forma, pretende-se evidenciar como a estrutura tributária impacta no perfil distributivo medido pelas rendas do trabalho, avaliando-se alterações no índice de Gini após a incidência de impostos e de transferências, incluindo alguns dados para efeito de comparação internacional.
\end{abstract}

\author{
Fernando Augusto Mansor de Mattos \\ Doutor em Ciência Econômica pela \\ Universidade Estadual de Campinas, \\ (UNICAMP). Estágio Pós-Doutoral na \\ Universidade de Columbia - EUA. Professor do \\ PPG em Economia e professor visitante do PPG \\ em Ciência Política da Universidade Federal \\ Fluminense (UFF). \\ Niterói, RJ - BRASIL \\ fermatt1@hotmail.com \\ orcid.org/0000-0002-1196-3246
}

Natassia Nascimento

Doutoranda em Economia na Universidade

Federal do Rio de Janeiro (UFRJ).

Rio de Janeiro, RJ - BRASIL

natassia18@gmail.com

orcid.org/0000-0002-2146-7879

Palavras-chave: Salário Mínimo. Mercado de Trabalho.

Estrutura Tributária. Distribuição de Renda.

Desigualdade.

\section{Para citar este artigo:}

MATTOS, Fernando Augusto Mansor de; NASCIMENTO, Natassia. Mercado de trabalho, salário mínimo e estrutura tributária: impactos sobre o perfil distributivo brasileiro em perspectiva histórica. Tempo e Argumento, Florianópolis, v. 11, n. 27, p. 429 - 474, maio/ago. 2019. 


\title{
Labor market, minimum wage and tax structure: impacts on Brazilian distributive profile of incomes in historical perspective
}

\begin{abstract}
This article seeks to highlight historical aspects related to the evolution of the minimum wage, the dynamics of the labor market and changes in the tax structure since mid-twentieth century and its effects on Brazil's income distribution profile. The first part analyzes the Gini index and its evolution from 1960 on, emphasizing the role played by the minimum wage in determining the trajectory of the distributive profile described by the Gini index. In the second part, a historical retrospective assembly of the current tax structure is made, especially the tax reform of 1967 , which consolidates the foundations on which the tax structure rests today. In this way, it is intended to show how the tax structure impacts the distributive profile measured by work income, evaluating changes in the Gini index before and after the incidence of taxes and transfers, including some data for international comparison.
\end{abstract}

Keywords: Minimum Wage. Labor Market. Tax Structure. Income Distribution. Inequality.

\footnotetext{
* A redação deste artigo representou o primeiro esforço organizado empreendido para a elaboração de um projeto de pesquisa (intitulado "Economic Inequality and Income Distribution") que seria (e foi) submetido ao Institute of Latin American Studies (ILAS), na Universidade de Columbia, em Nova Iorque (EUA), onde o primeiro autor atuou como Visiting-Scholar entre julho de 2017 e junho de 2018. Versões um pouco modificadas da atual foram apresentadas em diversos encontros acadêmicos no Brasil nos anos de 2016 e 2017. A atual versão inclui resultados que representam desdobramentos da pesquisa empreendida em Columbia. Outros artigos com resultados do referido projeto poderão ser enviados para outras revistas acadêmicas do Brasil e do exterior, bem como também novamente para esta revista, respeitados os critérios de publicação por ela adotados.

** Os assuntos tratados nesse artigos estão registrados no Journal of Economic Literature com os códigos N36 (Latin America and Caribbean) e J31 (Wage level and Structure/Wage Differencials).

*** Os autores agradecem aos dois pareceristas anônimos que leram a primeira versão deste artigo, deixando sugestões importantes para esta redação final.
} 


\section{Apresentação}

A literatura internacional que trata do tema da distribuição de renda e da desigualdade econômica teve, nos anos 2000, a América Latina como uma de suas principais preocupações, dadas as peculiaridades dos países da região, pois, ao mesmo tempo em que nesta área do mundo se concentram os países de maior desigualdade econômica, também foram os únicos que, no referido período, exibiram melhorias de seus perfis distributivos, embora ainda conservando níveis de iniquidades que permanecem entre os mais altos do mundo (IMF, 2017).

Tal realidade merece de fato uma atenção especial, tanto para que se possam explicar as razões das modificações distributivas ocorridas, quanto para que se compreendam os desdobramentos dessas alterações no futuro, bem como seus efeitos sobre o próprio desenvolvimento econômico da região. A forma metodologicamente mais adequada para avaliar esse fenômeno é colocá-lo em perspectiva histórica, buscando compreender as características estruturais que moldam perfis distributivos tão desiguais. A análise de cada caso dos países que fazem parte da América Latina ${ }^{2}$ enriquece a análise, pois permite estudar movimentos gerais que promoveram as mudanças de perfil distributivo (em grande medida decorrentes do ciclo de commodities havido nos anos 2000 e produzido especialmente pela demanda chinesa) e também destacar especificidades nacionais 3 .

Este artigo pretende estudar alguns aspectos do caso brasileiro. As modificações recentes no perfil distributivo estimulam o debate sobre o tema justamente porque representam um movimento pouco comum na trajetória histórica da desigualdade de renda no Brasil, sociedade marcada, desde a sua constituição, sob o signo da concentração da renda e da riqueza.

A complexidade da questão da desigualdade, ainda mais em um país com as características do Brasil, de passado escravista e industrialização tardia, exige uma abordagem conceitual e empiricamente ampla do tema. As mais recentes pesquisas de

\footnotetext{
${ }^{1}$ Como fazem, por exemplo, Frankema (2009) e Bertola (2010).

2 Conforme ocorre no número especial da revista acadêmica colombiana Cuadernos de Economía (BOGLIACINO; ROSSI, 2017).

3 Como, por exemplo, o trabalho de Lustig, Lopez-Calva e Ortiz-Juarez (2013) e diversos outros trabalhos dos autores.
} 
especialistas brasileiros no assunto $^{4}$ vêm destacando a necessidade de um aprofundamento dos estudos da evolução recente do perfil distributivo, interpretando-o segundo diferentes indicadores e pontos de vista. Da mesma forma, a literatura internacional $^{5}$ e em especial alguns estudos produzidos por instituições internacionais vêm ressaltando que o tema da desigualdade deve ser discutido sob uma perspectiva multidimensional, sendo o aspecto econômico apenas um dentre outros, conforme se depreende, por exemplo, da leitura de documento publicado pelas Nações Unidas (UN, 2005).

O objetivo deste trabalho é analisar aspectos históricos da desigualdade econômica brasileira, utilizando tanto indicadores de renda auferidas no mercado de trabalho, quanto indicadores de distribuição de renda mediados pelos efeitos da estrutura tributária brasileira. O que justifica a inclusão de dados relacionados à estrutura tributária é o reconhecido caráter regressivo da mesma na sociedade brasileira6 ${ }^{6}$. Conceitualmente, o que referenda a escolha dessa abordagem é uma postura consagrada na literatura internacional, desde, pelo menos, meados do século XX, de avaliar o perfil distributivo a partir do conceito de renda disponível7, um dos aspectos incluídos em

\footnotetext{
4 Ver, por exemplo, trabalhos reunidos por Barros, Foguel e Ulyssea (2007, 2008), assim como Dedecca, Jungbluth e Trovão (2008), Dedecca (2010, 2009, 2007) e Medeiros, Castro e Souza (2015), entre outros.

${ }^{5}$ Como, por exemplo, o recentemente publicado em português Piketty (2015) e sua obra mais famosa, Piketty (2014).

${ }^{6}$ Conforme se depreende, entre outros trabalhos, de IPEA (2009a, 2009b, 2011a, 2011b), de Varsano (1996) e de Zockun (2005), sem olvidar o já clássico estudo de Oliveira (1981).

7 Apropriadamente, OECD (2008) define a renda disponível como a renda auferida no mercado (trabalho, previdência e também transferências públicas de renda) e também composta por rendimentos auferidos pelos indivíduos e/ou famílias decorrentes da posse de ativos financeiros e não financeiros. Neste artigo, pretende-se comparar as alterações ocorridas nos indicadores de desigualdade de renda do Brasil (e de países selecionados) levando-se em conta apenas o critério da incidência de impostos e de transferências (ou seja, alterações nos indicadores de desigualdade de renda do trabalho, de diferentes países, antes e depois da cobrança dos impostos e da ocorrência de transferências por parte das políticas públicas). As dificuldades metodológicas para construir indicadores mais precisos de renda disponível, como, por exemplo, a falta de uma variável específica para rendimentos de caráter financeiro nos questionários do IBGE, conforme reclamam Dedecca, Jungbluth e Trovão (2008), impedem, por ora, um avanço maior no sentido de uma avaliação mais acurada do aspecto econômico da desigualdade brasileira e de sua evolução recente. Mostrase urgente a necessidade de se elaborar uma avaliação mais abrangente e multidimensional acerca da evolução da desigualdade brasileira ocorrida nos últimos anos, após período de indiscutível redução da desigualdade de renda medida pelos indicadores de rendimentos obtidos no mercado de trabalho no Brasil. Tal realidade representou uma importante reversão de trajetória do perfil distributivo brasileiro, mas que sem dúvida ainda merece ser reestudada de forma mais detalhada, conforme fizeram, por exemplo, Medeiros, Castro e Souza (2015). Deve-se sublinhar que a comparação do indicador de desigualdade da renda bruta com o indicador de desigualdade da renda líquida representa uma ferramenta muito importante para
} 
importante e histórico debate travado entre Hicks (1939, 1940, 1948) e Kuznets (1948a, 1948b).

Para cumprir o referido objetivo, este artigo está dividido em duas partes. $\mathrm{Na}$ primeira parte, é analisada a evolução do índice de Gini desde 1960 até o presente, destacando, nesse contexto, qual o papel que teve o salário mínimo ${ }^{8}$ na determinação dos movimentos no perfil distributivo descritos pelo Gini 9 . Na segunda parte, é feita uma retrospectiva histórica da montagem da atual estrutura tributária, destacando-se a Reforma Tributária de $1967^{10}$, que consolida as bases sobre as quais se assentam a estrutura tributária até hoje. Nesta segunda parte, alguns indicadores do perfil distributivo, mediados pela incidência de impostos e de transferências, são analisados, incluindo dados para uma em breve comparação internacional.

O advento da formação de Estados de Bem Estar Social, notadamente na Europa desenvolvida, consagrou essa forma de avaliar a desigualdade econômica nesses países, dado o reconhecimento de que tal fenômeno não deveria ser medido apenas pelos rendimentos auferidos no mercado de trabalho, como também pelos resultados gerados

avaliar a efetiva progressividade das políticas públicas, em especial da política fiscal (ou seja, como a renda é tributada e também como e em que tipos de políticas sociais são efetivados os gastos públicos). Trata-se de um instrumento que permite comparar diversos elementos da desigualdade econômica, conforme pretendemos fazer aqui, revelando uma preocupação não apenas com as rendas do trabalho, mas também com outras esferas e dimensões da distribuição de renda, situação particularmente característica da elevada (e complexa) desigualdade brasileira.

8 A Lei que cria o salário mínimo no Brasil pode ser encontrada no seguinte link: https://www2.camara.leg.br/legin/fed/lei/1930-1939/lei-185-14-janeiro-1936-398024-publicacaooriginal-1-

pl.html. Também pode ser acessado o seguinte link http://www.fgv.br/Cpdoc/Acervo/dicionarios/verbetetematico/lei-do-salario-minimo, para acesso a verbete do acervo do CP_DOC da FGV, que trata da criação do salário mínimo no Brasil. Souen (2013) também apresenta uma excelente retrospectiva histórica da evolução do salário mínimo e de seu contexto.

9 A justificativa para se tomar a trajetória histórica do salário mínimo real como referência para avaliar a evolução do perfil distributivo brasileiro está referendada pela literatura que revela não apenas forte correlação entre os indicadores (salário mínimo real e diferentes indicadores de perfil distributivo), como também que destaca ter tido o salário mínimo, historicamente (e até o presente), papel decisivo na determinação de ampla parcela dos salários e rendimentos auferidos no mercado de trabalho brasileiro, dadas as caraterísticas do mesmo: ampla base de baixos salários e rendimentos; relações de trabalho historicamente desregulamentada; presença de parcelas expressivas vivendo na informalidade; existência de acelerada rotatividade da mão de obra. Souza (1980) advoga o papel exercido historicamente pelo salário mínimo como um "farol" na determinação de outros rendimentos do espaço ocupacional urbano e rural; da mesma maneira, Souza e Baltar (1979), Sabóia (1985), Carneiro e Faria (1997), Cacciamali (2005) e Cacciamali, Portela e Freitas (1994) abordam o tema.

10 Sobre aspectos jurídicos da Reforma Tributária de 1967, incluindo comentários e análise sobre seus antecedentes e também seus desdobramentos posteriores, podem ser encontrados em Santos (2015). 
pelas políticas fiscal (gastos feitos pelos respectivos Estados Nacionais) e tributária (forma como são cobrados os impostos dos cidadãos de diferentes classes sociais e também das pessoas jurídicas). No Brasil, essa forma de se medir a evolução e o perfil da desigualdade não é muito comumente encontrada em estudos sobre desigualdade econômica, apesar do evidente caráter regressivo da tributação, que se soma à expressiva desigualdade gerada pelo mercado de trabalho. Dessa forma, justifica-se a inclusão de uma avaliação do papel exercido pela estrutura tributária sobre o perfil distributivo, dada a relevância deste esforço e sua ainda pequena presença em estudos sobre desigualdade econômica. Nas conclusões, são feitas algumas considerações procurando destacar os condicionantes históricos tanto do processo de determinação do valor real do salário mínimo, como da evolução da estrutura tributária brasileira, reforçando o papel de ambos na determinação do perfil distributivo brasileiro.

\section{Evolução histórica da desigualdade econômica medida pela evolução da renda pessoal}

A trajetória do perfil distributivo brasileiro (avaliada segundo as rendas obtidas no mercado de trabalho), colocada em perspectiva histórica, pode ser ilustrada pelo gráfico I, que apresenta, a evolução do índice de Gini e da renda per capita desde 1960, a partir de quando há informações disponíveis para o Gini ${ }^{11}$.

Através da análise conjunta dos dois indicadores, pode-se ter uma retrospectiva do comportamento da desigualdade brasileira à medida que se processava o desenvolvimento econômico nacional ${ }^{12}$. O gráfico mostra nitidamente três diferentes

\footnotetext{
${ }^{11} \mathrm{O}$ Índice de Gini é uma das medidas mais conhecidas de desigualdade para uma amostra de dados. Ele varia de ZERO (extrema igualdade) a UM (extrema desigualdade). Quando o índice é igual a UM, significaria a hipotética situação em que um único indivíduo detivesse toda a renda da economia e os demais não tivessem nada; no caso hipotético de Gini igual a ZERO, significaria que todos os indivíduos da economia teriam exatamente a mesma renda. Os dados de Gini aqui expostos medem a desigualdade das rendas do trabalho, não informando nada sobre a chamada distribuição funcional da renda, ou seja, sobre a repartição da renda nacional entre lucros e salários. No Brasil, tanto a desigualdade entre as rendas do trabalho (forma mais habitual de se medir a desigualdade na maioria dos países) quanto a desigualdade funcional da renda estão entre as mais altas do mundo. Muitos estudos indicam que a uma elevada desigualdade na distribuição funcional se relaciona também uma elevada desigualdade na distribuição das rendas do trabalho, mas essa problemática não será discutida neste artigo. Para mais detalhes sobre esse ponto específico, ver: Mattos (2005), Mattos e Cardoso (1999), Piketty (1995) e Piketty (2014).

${ }^{12}$ A renda per capita representa uma medida do grau de desenvolvimento econômico do país.
} 
padrões de comportamento da combinação entre desigualdade de renda e desenvolvimento econômico desde meados do século XX até o início dos anos 2000.

Um primeiro padrão - parte (1) - é delimitado pelo primeiro ano da série (1960) e o ano de 1980, que foi o último de crescimento expressivo do PIB real na história brasileira $(9,2 \%)^{13}$. Na parte (1) do gráfico percebe-se nitidamente um significativo crescimento do PIB per capita (notadamente a partir de 1967, ano em que se inicia o chamado "milagre" brasileiro) ao lado de uma importante ampliação da desigualdade de renda medida pelo Índice de Gini (somente em parte revertida nos últimos anos desse período) ${ }^{14}$. Nesse intervalo de 20 anos, ocorreram importantes modificações tanto na estrutura produtiva como também na estrutura ocupacional, pois o processo de industrialização então em curso, que permitiu que a renda real per capita no período crescesse a cerca de $4,6 \%$ ao ano ${ }^{15}$, em média, foi acompanhado de formalização do mercado de trabalho, medida pela ampliação do peso relativo do assalariamento com carteira assinada no conjunto dos ocupados (POCHMANN, 1999). Foi nesse período também que o Brasil se tornou predominantemente urbano, passando de um índice de $45 \%$ da população vivendo nas cidades em 1960, para 56\% em 1970 e 68\% em 1980. O ritmo de criação de postos de trabalho na Indústria de Transformação cresceu a uma taxa média anual de cerca de 5,3\%, o que favoreceu o processo de formalização do mercado de trabalho acima mencionado, pois, nas atividades industriais, a contratação com carteira assinada tem um peso maior do que em qualquer outra das atividades produtivas. A despeito da ampliação da

${ }^{13}$ Crescimento do PIB real significa o crescimento do PIB descontado dos efeitos da inflação. A variação nominal do PIB não retira os efeitos da alta de preços sobre o cálculo do produto interno bruto. Para efeito de comparação interanual da evolução da renda em uma economia, usa-se a variação real do PIB.

14 Tese de Doutoramento de Souza (2016) apresenta um esforço pioneiro de tentativa de reconstituir novas séries históricas para descrever a evolução da distribuição de renda no Brasil, usando, para tal tarefa, dados de tributação do Imposto de Renda, com o intuito de compreender a evolução da apropriação de renda pelo topo da distribuição. Apesar das limitações metodológicas reconhecidas pelo próprio autor, seu trabalho chama a atenção para a relação entre Democracia e concentração/distribuição de renda no Brasil, tema que ainda merece muitos outros trabalhos de pesquisa, apesar (ou por isso mesmo) da debilidade da disponibilidade de dados. Entre as principais conclusões do autor, destacam-se as afirmações segundo as quais a fração da renda apropriada pelo $1 \%$ mais rico teria aumentado durante o Estado Novo e ainda durante a II Guerra, tendo diminuído no imediato pós-II Guerra e, ainda segundo ele, tendo se reduzido mais ainda na segunda metade dos anos 1950; tal trajetória, segundo os dados organizados na Tese, foi revertida após a instauração do regime de 1964, quando o nível de apropriação da renda pelos muito ricos ( $1 \%$ mais alto) teria regredido ao mesmo patamar de quase duas décadas anteriores.

${ }^{15}$ Este e demais dados a seguir mencionados foram calculados a partir das estatísticas históricas oficiais do IBGE. 
desigualdade, o período 1960-1980 mostrou significativa mobilidade intergeracional, na esteira do processo de industrialização, que permitiu melhoria das condições sociais médias das famílias brasileiras. Não obstante, os dados inequivocamente revelam que a repartição dos frutos do desenvolvimento foi extremamente desigual, e para esse resultado teve papel decisivo o contexto político e econômico do governo civil-militar instalado no golpe de $1^{\circ}$ de abril de 1964. A melhoria ocorrida no perfil distributivo no final dos anos 1970 foi não apenas modesta (a desigualdade no final dos anos 1970 ainda era bem maior do que no início dos anos 1960), como também inconsistente e efêmera ${ }^{16}$, conforme se percebe ao analisar os dados dos anos $1980^{17}$.

Um segundo padrão é delimitado pelos anos 1980 e 2003, quando o PIB per capita real cresce muito modestamente, a cerca de apenas 0,25\% ao ano em média, tendo apontado uma trajetória descendente tanto no início dos anos 1980 quanto no início dos anos 1990, ambos marcados por recessões econômicas. No período assinalado como parte (2) do gráfico I, a desigualdade oscilou em torno de um patamar bastante elevado, mostrando sinais de modesto declínio somente no final do período (ou seja, já no início do século XXI). Esse período foi permeado pela democratização do país, que infelizmente coincidiu com a crise da dívida externa deflagrada no início dos anos 1980, a qual legou, para toda a década, uma herança marcada por crescimento econômico pífio, acompanhada de desestruturação do mercado de trabalho (aumento da informalidade e queda real dos rendimentos do trabalho em vários momentos do período). Interrompia-

\footnotetext{
${ }^{16}$ Bonelli e Ramos (1993) atribuem essa queda do índice de Gini no final dos anos 1970 ao fato de ter coincidido com a abertura política, ao ressurgimento do movimento sindical e - em grande medida por isso mesmo - a mudanças nas regras de reajustes salariais definidas pelo Estado, com a introdução de reajustes semestrais de salários (e não mais apenas anuais, como vinha acontecendo desde o início do governo militar instalado em 1964) quando a inflação mostrava ter galgado patamares mais elevados. Com relação à retomada da trajetória ascendente da desigualdade nos anos 1980, especialmente nos anos finais dessa década, os autores se incluem entre os vários estudiosos que a explicam principalmente pelo recrudescimento inflacionário (e ao baixo crescimento econômico) ocorrido no período. O trabalho de Almeida (2018) apresenta uma avaliação ideologicamente diferente em comparação com o trabalho anteriormente citado, e também coloca a questão dos reajustes salariais em um contexto mais amplo, destacando o papel da abertura política (final dos anos 1970/início dos anos 1980) e da crise externa enfrentada pelo Governo Figueiredo no "afrouxamento" das regras de reajustes salariais. Da mesma forma que Almeida (2018), Secco (2018) destaca o contexto de surgimento do PT e da CUT, no âmbito de abertura política. Tais trabalhos iluminam o debate sobre a trajetória da economia a partir dos anos 1980.

${ }^{17}$ Entre 1977 e 1981, o índice teve uma queda de cerca de 6\%, mas ele volta a subir entre 1981 e 1985, quando cresceu quase $3 \%$ e, depois, mais cerca de $7 \%$ entre 1985 e 1989, quando atingiu o índice mais alto da série: 0,636 .
} 
se, também, o processo de mobilidade social que havia marcado a sociedade brasileira nos anos da industrialização e do chamado nacional-desenvolvimentismo.

Nos anos 1990, o crescimento médio anual do PIB seria ainda menor do que na década imediatamente anterior, com o agravante de que o emprego industrial caiu vertiginosamente, tanto durante a recessão do início da década, quanto ao longo da mesma, com a aplicação da política econômica pós-implementação do Plano Real (1994) (BALTAR, 2003).

Gráfico 1

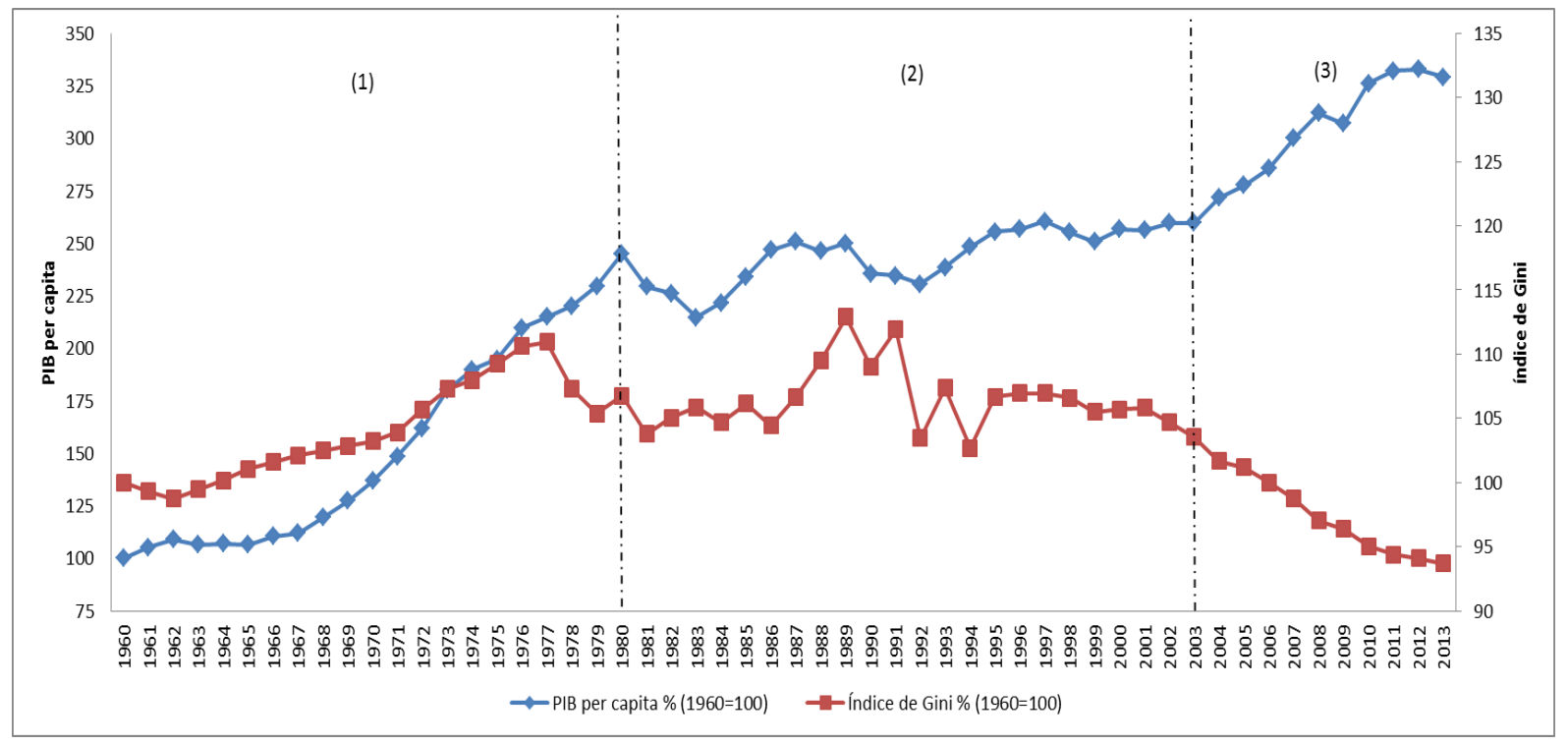

Fonte: Microdados da PNAD (IBGE); Censos Demográficos e Langoni (1973). Adaptado de Pochmann (2012).

A tão almejada estabilização de preços foi viabilizada pela mudança dos fluxos financeiros internacionais, permitindo ao Brasil e a diversos outros países ancorar sua moeda no dólar, estabilizando os preços internos. Não obstante, no caso brasileiro, esse período de trégua da escalada dos preços não foi acompanhado de medidas que viabilizassem a criação de um novo padrão de acumulação tendo a atividade industrial como o centro do processo de desenvolvimento. Ademais, o Plano Real não continha, na sua formulação, mecanismos explícitos de distribuição de renda e o arco de alianças políticas que o sustentou não revelou compromisso com melhoria do perfil distributivo. 
Conforme se verifica no gráfico I, o período pós-estabilização ocorrido em 1994 mostrou apenas uma modesta redução da desigualdade, embora esse não tenha sido sequer um dos objetivos do Plano Real. Mattos e Cardoso (1999) apontaram que essa efêmera e modesta melhoria do perfil distributivo pós-Plano Real deveu-se à valorização cambial que ocorreu logo após o lançamento da nova moeda e também aos efeitos - não previstos - dessa mudança de preços relativos na economia sobre o mercado de trabalho, o qual tem uma peculiaridade: uma elevada presença, em sua base ocupacional, de trabalhadores de setores de serviços e de comércio de setores não organizados (informais) da economia. A valorização cambial e a recuperação da atividade econômica ocorrida logo após a estabilização da inflação acabariam por favorecer a renda do trabalho dos vendedores de serviços e dos profissionais autônomos, mas esse efeito durou apenas pelo curto período de retomada econômica pós-estabilização. Mattos e Cardoso (1999) mostram que os ocupados dos setores de serviços pessoais e outras atividades que não sofriam a concorrência de produto/serviços importados conseguiram obter (pelo menos enquanto durou o período de retomada do crescimento da economia brasileira pós-estabilização de 1994, ou seja, até meados de 1997) um aumento de remuneração um pouco maior do que ocorreu com os salários dos setores mais organizados da economia, como o setor industrial, por exemplo. Tal setor passou a sofrer os efeitos da concorrência de produtos importados a câmbio baixo, o que acabou debilitando o poder de barganha dos seus empregados, porque também tiveram que passar a discutir reajustes salariais sob o impacto da livre negociação implementada após a estabilização.

Sendo assim, já que a base do mercado de trabalho possui elevada participação de trabalhadores nos setores de serviços, um aumento de sua renda acima da média dos reajustes salariais acabaria por reduzir a desigualdade de rendimentos do trabalho, pelo menos enquanto a economia se mantivesse aquecida. Essa redução da desigualdade só não foi mais expressiva porque não houve uma recuperação significativa do salário mínimo - e também porque a retomada da atividade econômica não foi duradoura.

Dessa forma, a pequena e pouco duradoura melhoria do perfil distributivo, indicada pela queda do índice de Gini entre 1995 e 1998, deveu-se a circunstâncias 
fortuitas relacionadas à excessiva valorização cambial e ao fato de o mercado de trabalho ser desestruturado. Essa mudança de preços relativos representou, portanto, a principal explicação para a melhoria do perfil distributivo nos três anos seguintes à implementação da nova moeda. Esse fenômeno se desvaneceu rapidamente, à medida que a economia perdia dinamismo e que o desemprego aumentava, diante das contradições de uma política econômica que se baseou no binômio juros altos-câmbio valorizado e que também importante destacar - não criou mecanismos explícitos de formatação de políticas públicas dedicadas à redução das desigualdades sociais e econômicas existentes no país.

Deve-se assinalar, também, que a significativa expansão da população urbana no período (2) no gráfico I (crescimento de cerca de 2,6\% ao ano, em média, entre 1980 e 2000), em contexto de desaceleração da atividade econômica e de desindustrializaçãao ${ }^{18}$, promoveu novos movimentos de desestruturação dos mercados de trabalho urbanos ${ }^{19}$, ao mesmo tempo em que, nas atividades agrícolas, dada a falta da reforma agrária por um lado, e a expansão de diversos segmentos do agronegócio de outro, ocorreu a ampliação das diferenças intra e inter setoriais de produtividade, com queda, em números absolutos, do total de ocupados no setor rural (BELIK; BALSADI; BORIN; CAPANHOLA; DEL GROSSI; SILVA, 2003).

No referido período não ocorreu uma piora do perfil distributivo ${ }^{20}$, comparando-se exclusivamente os anos extremos da década, mas a estabilização da desigualdade em patamares muito altos, em contexto de um modesto crescimento da renda per capita, o que promoveu a piora das condições sociais ao longo do período. O baixo crescimento econômico da década de 1990 resultou em aumento do desemprego, um aspecto central

\footnotetext{
${ }^{18} \mathrm{O}$ total de pessoal ocupado na indústria de transformação caiu de cerca de 4,9 milhões de trabalhadores, em 1980, para apenas 3,1 milhões em 1995. Dados oficiais do IBGE - Estatísticas Históricas.

19 Uma ilustração desse fenômeno está, por exemplo, no fato de que a participação das ocupações por contaprópria no conjunto dos ocupados, passou de 18,4\% para 22,5\% entre 1989 e 1999, segundo dados das respectivas PNADs. No mesmo intervalo de tempo, a participação do emprego doméstico subiu de $8,4 \%$ para 9,9\%. Com relação às ocupações assalariadas, verificou-se, no mesmo intervalo, uma queda generalizada do grau de formalização em todos os setores de atividade investigados pelas PNADs, conforme mostrou Baltar (2003).

${ }^{20}$ O Gini de 1980 era igual a 0,601, atingindo o ponto mais alto da série em $1989(0,636)$, não por acaso, o ano de auge do processo inflacionário; mas, voltou a 0,595 em 2000 e encerrou o referido período com 0,583, em 2003.
} 
da desestruturação ocorrida no mercado de trabalho. Esses fatores foram determinantes para a manutenção de uma elevada desigualdade na última década do século XX (DEDECCA, 2003).

Finalmente, um terceiro padrão pode ser percebido a partir de 2003, quando se conjugam uma trajetória ascendente do PIB real per capita de cerca de 2,4\% entre 2003 e 2013 (bem menor do que a que vigorou nos anos da industrialização sob o nacionaldesenvolvimentismo, porém, também diferente - e maior - do que a do período marcado pela parte (2) no gráfico I) com uma trajetória de redução da desigualdade da renda do trabalho (o Gini caiu pouco mais que 10\% entre 2003 e 2013). Essa redução da desigualdade, porém, foi suficiente somente para recolocá-la em patamar semelhante ao que vigorava antes de 1964 .

Existe uma ampla literatura que se debruça na investigação sobre as causas e a dimensão dessa queda de desigualdade, que tem sido analisada sob diversos pontos de vista $^{21}$. A forma mais habitual de interpretá-la ainda é a que leva em consideração a desigualdade pessoal da renda, tomando-se como fonte de informação a renda declarada nas pesquisas domiciliares, como as PNADs e os Censos, por exemplo. Nesses casos, os rendimentos têm como origem, principalmente, a renda do trabalho e aquelas provenientes de transferências definidas pelas políticas públicas.

O que se verifica, na área delimitada pela parte (3) do gráfico I, é que de fato houve redução da desigualdade pessoal da renda no período em questão. Existe razoável consenso de que a redução recente da desigualdade foi determinada por fatores pertinentes à dinâmica do funcionamento do mercado de trabalho (retomada de um processo de formalização do trabalho, com ampliação do peso do emprego com carteira no conjunto da ocupação; redução do desemprego; desaceleração do número de entrantes no mercado de trabalho, tanto por motivos econômicos quanto também por razões demográficas) e também por elementos relacionados às transferências de renda

\footnotetext{
${ }^{21}$ Um primeiro trabalho de fôlego dedicado a compreender esse fenômeno recente foi o estudo organizado por Barros, Foguel e Ulyssea (2007) e Barros, Foguel e Ulyssea (2008), nos quais estão reunidos trabalhos de diversos pesquisadores com diferentes formações teóricas e que também analisam o problema da desigualdade brasileira sob diversos pontos de vista.
} 
ocorridas para as classes populares, na forma de programas como o Bolsa Família e outras transferências, principalmente os relacionados ao sistema previdenciário.

A ampliação do valor real do salário mínimo teve impacto positivo nestas duas vertentes (mercado de trabalho ${ }^{22}$ e transferência de renda via políticas públicas, cujos valores estão ancorados no salário mínimo). O que se debate, no momento atual, é qual o peso explicativo de cada um dos dois aspectos. Além disso, também tem havido uma ampliação do escopo da interpretação da desigualdade, procurando compreender as várias formas de sua manifestação, conforme será mencionado nas conclusões deste artigo.

Antes disso, vale interpretar os dois próximos gráficos, através dos quais a análise da evolução histórica do valor real do salário mínimo pode fornecer mais informações a respeito da evolução da desigualdade brasileira nas últimas décadas. O gráfico II apresenta a evolução do valor real do salário mínimo desde sua implementação até o ano de $2013^{23}$. Os dados revelam significativas alterações ao longo do período, tendo atingido seus maiores valores nos tempos do chamado nacional-desenvolvimentismo dos anos 1950 e seu valor mais baixo no final do governo Dutra. Registraram-se também quedas importantes logo no início do governo instalado em 1964 e, anos depois, durante o momento mais agudo da aceleração inflacionária, que correspondeu aos anos 1980 e à primeira metade dos anos 1990. Por fim, percebe-se uma lenta recuperação a partir da segunda metade dos anos 1990 e uma ascensão mais significativa a partir de 2005/200624.

Uma breve descrição da história de implementação do salário-mínimo e das políticas que o definiram permite compreender a trajetória descrita no gráfico II.

\footnotetext{
${ }^{22}$ Deve-se registrar que pesquisas e formulações teóricas feitas ao longo dos anos 1970 e 1980 defenderam a ideia (respaldada em evidências empíricas) de que o salário mínimo não afetava apenas a renda do assalariado formal do mercado de trabalho, mas também exercia uma importante função como "farol" das remunerações da pequena produção independente, e de todo um amplo espectro de mão de obra não qualificada, geralmente depositada no setor informal da economia. Tudo indica que o salário mínimo ainda venha mantendo esse papel até o presente, sendo possível também supor que assim o será no futuro. Daí o papel estruturante e relevante exercido pelas políticas de valorização do salário mínimo em um país cujo mercado de trabalho tem as características do mercado de trabalho brasileiro. Sobre esse assunto, ver Souza e Baltar (1979) e Baltar e Dedecca (1992).

${ }^{23}$ Os dados estão registrados em valores médios anuais, a preços de 2013.

${ }^{24}$ Trabalho já clássico de Singer (2012) descreve o compromisso histórico do PT e do que representava a candidatura Lula com o aumento ao valor real do salário mínimo e com a questão do enfrentamento da pobreza. O trabalho do autor recupera as origens do movimento sindical que surge nos anos 1980 , independente da anterior estrutura sindical brasileira.
} 
Gráfico 2

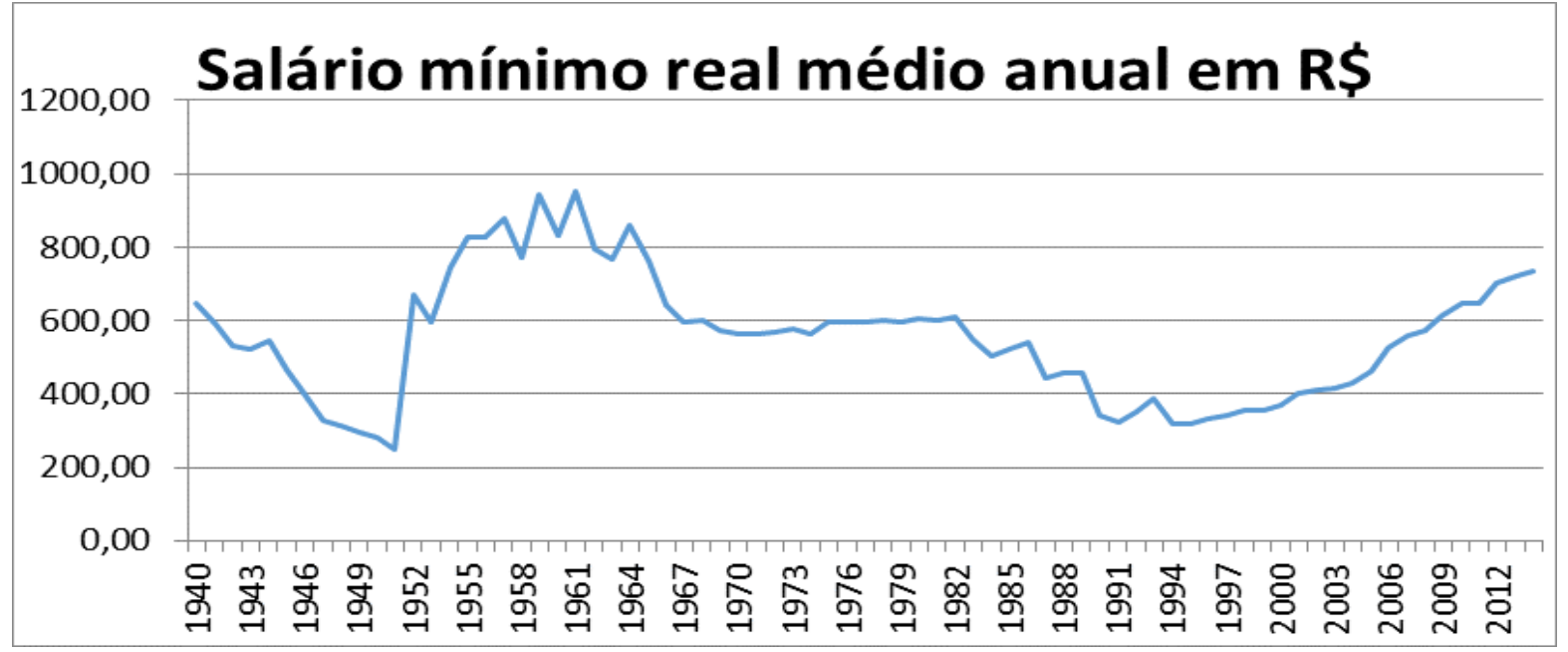

Fonte: IPEADATA; elaboração própria.

O salário mínimo foi instituído no Brasil no final dos anos 1930, mas foi a partir do Decreto-Lei $n^{\circ}$ 2.162, assinado por Getúlio Vargas, em $1^{\text {a }}$ de Maio de 1940, que passou de fato a vigorar (SOUEN, 2013). O salário-mínimo recebeu seu primeiro reajuste em julho de 1943 e o segundo em dezembro do mesmo ano. Depois disso, somente em dezembro de 1951, também sob a presidência de Getúlio, o salário mínimo seria novamente reajustado, passando seu novo valor a vigorar a partir de 1952 (SINGER, 1986). Depois disso, ocorreu o polêmico reajuste de maio de 1954 , em $100 \%$ de seu valor nominal, que havia sido precedido de grave crise política que levaria à demissão do então Ministro do Trabalho, João Goulart, em fevereiro ${ }^{25}$.

O governo Dutra não promoveu qualquer reajuste no salário mínimo. Ao final da década de 1940, portanto, dado que a inflação acumulada no período foi alta, notadamente por causa do período da II Guerra, o valor real do salário mínimo havia caído vertiginosamente, apesar de ter tido um aumento real importante em 1943 (no caso, ainda sob a primeira presidência de Getúlio Vargas). Na sua implementação, o salário mínimo tinha valor real semelhante ao salário médio na indústria de transformação (SOUEN, 2013). Ao final da década, porém, “o salário médio industrial já equivalia a 2,4 salários mínimos" (BALTAR; DEDECCA, 1992, p. 11).

\footnotetext{
25 Sobre os fatos envolvidos na discussão sobre o reajuste do salário mínimo de 1954 e sua dramática repercussão política, ver, pelo menos Skidmore (1982), Fonseca (1987), capítulo 6 e Bastos (2014).
} 
Nos anos 1950, dada a natureza das coalizões políticas que deram sustentação ao segundo Governo de Vargas e, depois, ao de Juscelino Kubitschek, houve uma política de sistemáticos reajustes dos valores reais do salário mínimo, no momento em que a economia vivenciava um importante crescimento do PIB e do PIB per capita, no contexto da instalação da industrialização pesada no Brasil. Verifica-se uma evolução positiva e expressiva no valor real do salário mínimo no período, sendo que, em 1959, ele atingiu aquele que é, até hoje, o maior valor histórico desde sua implementação ${ }^{26}$.

A partir dali, seguiu-se um período de acentuada retração de seu valor real, nos primeiros anos da década de 1960, por diferentes motivos. Entre 1960 e 1964, a economia passou por um período de estagnação e a crise política que assolou a sociedade brasileira também veio acompanhada de um aumento dos níveis de inflação, o que provocou perda do poder de compra dos salários, mesmo tendo o governo Goulart implementado três reajustes nominais no valor do salário mínimo ${ }^{27}$. Entre 1964 e 1967, houve expressiva redução do valor real do salário mínimo, na conjuntura da política salarial adotada pelo plano gradualista de combate à inflação do primeiro governo do regime de 1964 (BARONE; BASTOS; MATTOS, 2017). Ainda nos últimos três anos da década de 1960, embora a economia já estivesse se recuperando, o valor real do salário mínimo sofreu nova queda, adentrando os anos 1970 com um valor real cerca de $15 \%$ menor do que tinha quando fora criado, e cerca de metade do que foi o seu valor real mais alto, registrado em

\footnotetext{
${ }^{26}$ Deve-se ter em conta que os reajustes reais do salário mínimo, naquela época, afetavam principalmente os assalariados urbanos, tendo pouco impacto sobre os rendimentos do setor agrícola, numa época em que esse componente representava a maioria da população e parcela muito expressiva do mercado de trabalho brasileiro. De todo modo, os dados e gráficos mostram que os efeitos distributivos do salário mínimo foram significativos. Muitos anos depois - mais especificamente a partir da Constituição de 1988 -, a trajetória do salário mínimo passou a ter maior impacto sobre o conjunto do mercado de trabalho, pois ele passou a valer também para o setor agrícola, ao mesmo tempo em que se tornou referência para reajustar os valores das transferências sociais, em contexto de ampliação de políticas públicas que surgem como consequência da promulgação da Constituição Federal de 1988.

${ }^{27}$ Antes, o governo Vargas havia promovido dois reajustes no valor do mínimo (um em janeiro de 1952, de 200\% em termos reais, e outro que passaria a vigorar a partir de julho de 1954 , com reajuste de $100 \%$ nominais e que, na prática, representou uma valorização real de cerca de 70\% em relação a julho do ano anterior e de cerca de $37 \%$ em relação a janeiro de 1952, data do último reajuste até então), recuperando seu valor real após as significativas perdas provocadas no período Dutra. Depois de Getúlio, JK também promoveu mais dois reajustes (agosto de 1956 e janeiro de 1959) (SOUEN, 2013, p. 69), culminando no valor real mais alto da série histórica (janeiro de 1959) (no interregno Café Filho, não foi concedido nenhum reajuste do salário mínimo; idem para o breve período de Jânio Quadros). A seguir, em seu encurtado mandato, João Goulart concedeu mais três reajustes, os quais, porém, não lograram produzir aumentos reais expressivos, pois, os reajustes foram feitos em contexto de inflação alta e em aceleração, e em ambiente de estagnação econômica (SABOIA, 1985; SOUEN, 2013; BARONE, BASTOS, MATTOS, 2017).
} 
1959 (e cerca de 45\% menor, por exemplo, em comparação com o valor vigente em agosto de 1954, quando Vargas se suicidou).

Ao longo dos anos 1970, o valor real do salário mínimo manteve-se estável (gráfico II), apesar do intenso crescimento econômico e do PIB per capita no período. O seu valor real, porém, tornaria a perceber importante redução a partir do momento em que a economia brasileira começou a sofrer os efeitos da crise da dívida externa, no início dos anos 1980. Nos anos 1990, seu valor real tornava a cair, atingindo, em 1994, um de seus valores reais mais baixos de toda a série histórica (apenas em 1948, 1949, 1950 e 1951 o valor médio anual foi menor do que o de 1994). A partir da introdução do Plano Real, o poder de compra do mínimo voltou a recuperar-se, crescendo cerca de 3,8\% em termos reais ao ano, em média, entre 1995 e 2002, e cerca de 5,3\% ao ano, em média, entre 2003 e 2012.

Uma avaliação mais conclusiva a respeito da evolução do valor real do salário mínimo em perspectiva histórica, porém, pode ser feita quando analisada de forma conjunta com a trajetória da renda per capita. Dessa forma, pode-se perceber de forma mais clara os limites e os condicionantes do comportamento do poder de compra do salário mínimo, em cada contexto, bem como seus efeitos sobre o perfil distributivo.

\section{Gráfico 3}

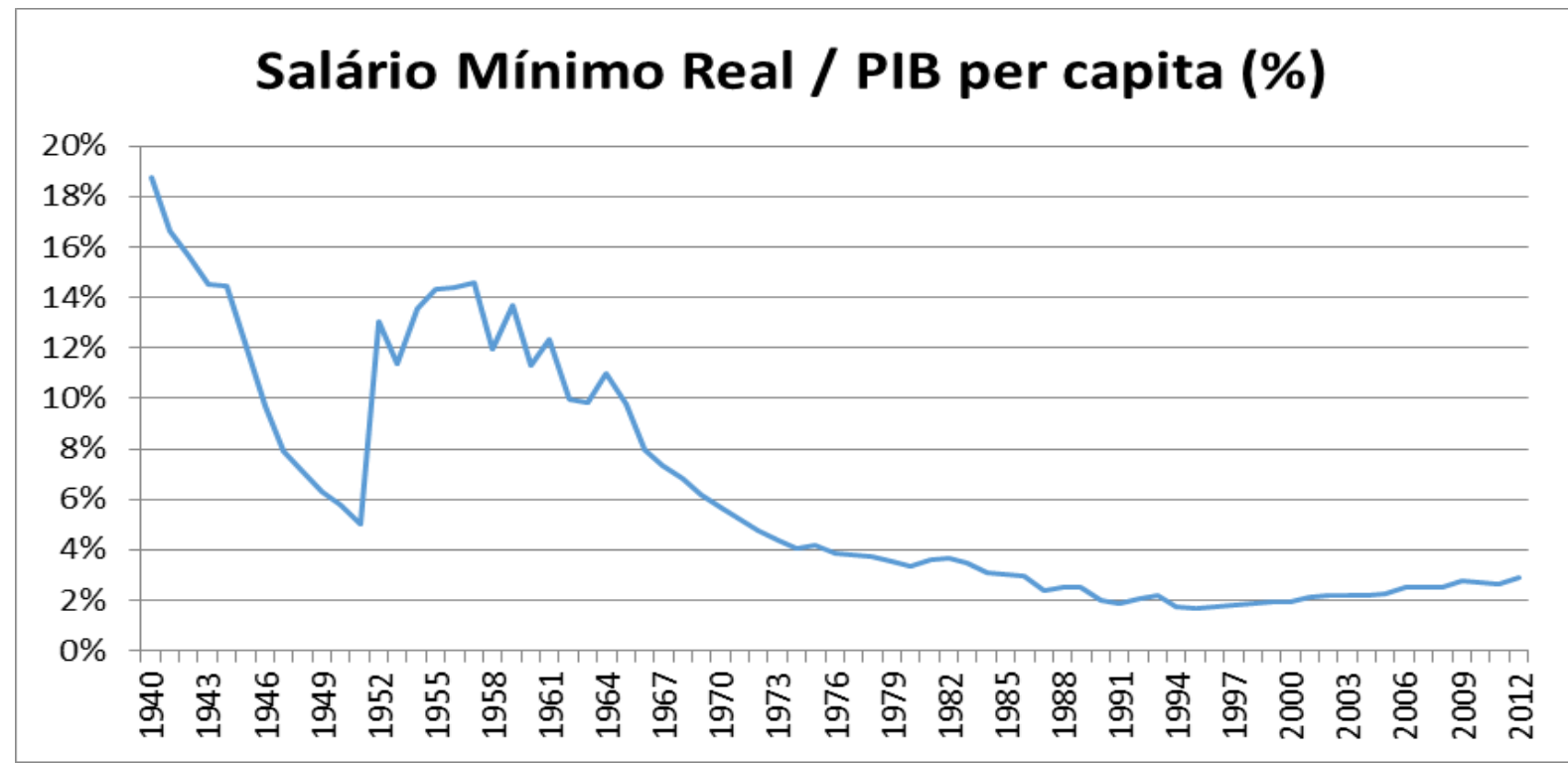

Fonte: IPEADATA; elaboração própria. 
Assim, o gráfico III demonstra de maneira mais elucidativa os movimentos do salário mínimo e permite uma avaliação relativa (e não absoluta, como no gráfico II) de sua evolução. A trajetória do indicador exposto no gráfico III (salário mínimo/renda per capita $^{28}$ ) permite aquilatar, de forma mais precisa, o potencial da evolução do salário mínimo a cada momento histórico, dada a evolução do nível de renda e da produtividade média da economia em cada período. Pode-se perceber, por exemplo, que a estabilidade expressa em seu valor real ao longo dos anos 1970, que foi revelada no gráfico II, na verdade escondia uma situação de ampliação da desigualdade de renda (e, de certa forma, de aumento da pobreza relativa para parcelas expressivas da população ${ }^{29}$ ) dentro da sociedade brasileira (conforme a evolução do índice de Gini, expressa no gráfico I, já havia sugerido), pois, a despeito de o valor real do salário mínimo de fato ter permanecido praticamente no mesmo patamar comparando-se o primeiro e o último ano da década de 1970 (gráfico II), ele se mostrava cada vez mais distante da renda per capita brasileira (gráfico III), no momento em que a economia crescia significativamente e em que o padrão de consumo se diversificava. O expressivo crescimento econômico e a diversificação do padrão de consumo aumentavam a percepção das necessidades de consumo diante de uma cesta básica de bens e serviços que se ampliava à medida que o país se desenvolvia, conforme salientou Singer (1986). Fica claro que, em princípio, havia mais amplas possibilidades econômicas de uma recuperação do valor real do salário mínimo, nos anos 1970, do que em outras épocas, e, se isso não ocorreu, foi pelos motivos políticos sobejamente conhecidos. Ao longo dos anos 1980, em contexto de perda de dinamismo econômico, queda dos rendimentos reais médios e aumento da informalidade, a distância entre o salário mínimo e a renda per capita brasileira continuou a aumentar (gráfico III) e esse distanciamento só não foi mais expressivo porque a renda per capita cresceu pouco naquele período.

Desse modo, registra-se que, se por um lado a literatura econômica batizou os anos 1980 como "a década perdida", devido aos lamentáveis índices de crescimento do PIB (ainda mais quando comparados aos que haviam vigorado desde, pelo menos, meados dos anos 1950 e também entre o final dos anos 1960 até o final dos anos 1970),

\footnotetext{
${ }^{28} \mathrm{O}$ dado percentual expresso no eixo esquerdo revela a relação entre o valor do salário mínimo mensal médio a cada ano (numerador) e a renda per capita do respectivo ano (denominador).

${ }^{29}$ Conforme argumenta Singer (1986), especialmente no capítulo III.
} 
poderíamos afirmar sem receio que, do ponto de vista da evolução do perfil distributivo, a "década perdida" foi a de 1970, pois, ali, em termos econômicos, estavam dadas as condições concretas para que o salário mínimo tivesse uma forte recuperação de seu valor real, mas o contexto político definido pelo arco de alianças de classes que participaram do golpe de 1964 optou deliberadamente pela retenção do valor real do salário mínimo, moldando um padrão de acumulação capitalista ancorado em uma crescente desigualdade econômica e de exclusão social.

Nos anos 1990, percebe-se que a relação salário mínimo/renda per capita mantevese estável, revelando que o Plano Real e a política econômica que a ele se seguiu não tinham uma preocupação explícita com a melhoria do perfil distributivo brasileiro. A partir de 2003, porém, e especialmente de 2005 em diante, a relação salário mínimo/renda per capita começou a subir, mas essa trajetória ascensional não foi tão expressiva quanto parecia denotar a trajetória do salário mínimo real, tomado isoladamente no gráfico II, no mesmo período. Isso leva a uma instigante questão acerca da real dimensão da melhoria do perfil distributivo dos anos mais recentes. A mudança positiva, em termos distributivos, é consensual, mas ainda precisa e merece ser aprimorada, em seus diversos aspectos, e interpretada em suas causas e limitações.

Um olhar atento para os dados referentes aos últimos anos registrados no gráfico I já sugeriam que, à medida que o crescimento econômico de 2004/2005 perdia dinamismo e levava a economia a uma quase estagnação, sob o primeiro mandato presidencial de Dilma Rousseff, o perfil distributivo (expresso pelo índice de Gini) parou de melhorar. Ficavam assim evidentes as dificuldades para continuar a promover melhorias consistentes e contínuas no perfil distributivo brasileiro (que ainda continua muito desigual) diante de um cenário de perda de dinamismo econômico.

A análise histórica apresentada neste artigo revela que o crescimento econômico (medido pelo PIB real ou, ainda mais adequadamente, pelo PIB real per capita) é condição necessária para a recuperação do salário mínimo. Muitos outros fatores econômicos e, principalmente, políticos também são intervenientes na determinação da trajetória do valor real do salário mínimo. Ademais, em um país como o Brasil, em que a informalidade no mercado de trabalho ainda é grande e em que já existe um razoável arcabouço 
institucional sob o qual se baseia a elaboração de políticas públicas, a determinação do salário mínimo é elemento central para a trajetória da renda e de sua distribuição, pois o mesmo não afeta apenas as ocupações formais do mercado de trabalho, mas também as do setor informal e os valores reais das transferências sociais. Assim, pode-se perceber que o valor real do salário mínimo continua afetando parcela ainda amplamente majoritária da população brasileira.

\section{A regressividade tributária no Brasil sob perspectiva histórica}

As características estruturais do atual sistema tributário brasileiro foram moldadas pela Reforma Tributária consolidada em 1967. Já no final dos anos 1950, eram evidentes os sinais de inadequação do então sistema tributário brasileiro, após décadas de significativo crescimento industrial e acelerada urbanização. Até o final da década de 1930, a maior parte da arrecadação do Estado brasileiro repousava em atividades relacionadas ao comércio exterior. A partir de 1930, com o "deslocamento do centro dinâmico" (FURTADO, 1959, cap. XXXII, p.205) representado pelo crescimento liderado pelo mercado interno e, em particular, pelas atividades industriais, diversas modificações foram feitas e todas elas tiveram como cerne a ampliação da base de arrecadação voltada para o mercado interno. Outra característica dessas alterações do sistema tributário no período pós-1930 foi a regressividade, com elevado peso de tributos indiretos (que incidem sobre consumo e vendas), ao invés da tributação direta (incidente sobre a renda e propriedade).

No final dos anos 1950, a inadequação do sistema tributário revelava-se sob diversos pontos de vista. No que se refere às questões de gestão da arrecadação, registra-se a ausência de correção monetária de imposto devido e em atraso, o que debilitava a efetiva capacidade arrecadatória do setor público. Também promovia deturpações no sistema tributário a incidência de impostos em cascata, ao invés de impostos por valor agregado - mais adequados a uma economia industrializada ${ }^{30}$. Do

\footnotetext{
30 Da leitura de Oliveira (1981) podem-se destacar como os principais problemas do sistema tributário anterior às reformas feitas nos anos 1960: a cumulatividade dos impostos sobre consumo; aumento progressivo do Imposto de Renda Pessoa Jurídica (IRPJ) e o aperto no Imposto de Renda Pessoa Física (IRPF), tanto com aumento das alíquotas quanto com mecanismos que evitassem a sonegação.
} 
ponto de vista social, também se podem tecer críticas àquela formatação do sistema tributário, pois o mesmo não carregava elementos mínimos de preocupação com a correção das distorções da elevada desigualdade de renda que marcou a industrialização brasileira (construída já após uma herança de elevada desigualdade existente desde a constituição do Estado nacional brasileiro).

Sob o governo João Goulart (1961-1964), a questão tributária se inseria no amplo leque de reformas sintetizadas sob a ideia das Reformas de Base, conjunto de mudanças propostas pelo seu governo para corrigir as conhecidas e denunciadas injustiças sociais brasileiras. Entre elas, destacava-se a Reforma Agrária, mais mencionada nos debates políticos da época e na interpretação histórica que se faz daquele período ainda hoje, mas não a única. Também uma reforma tributária, com a instalação de impostos progressivos, fazia parte do rol de reformas estruturais que tinham como objetivo não só o crescimento do PIB e o aprofundamento do Processo de Substituição de Importações, mas também a melhoria da distribuição de renda, formando mercado consumidor para ampliação da demanda de bens de consumo durável.

Através das propostas explicitadas no Plano Trienal, elaborado por Celso Furtado, alinhavam-se também medidas para tornar mais funcional o sistema tributário brasileiro (FURTADO, 2011). Muitas dessas propostas seriam absorvidas pela reforma tributária colocada em prática pelo governo de 1964, excetuando-se as mudanças voltadas a dotar o sistema tributário de maior poder de redução de desigualdades de renda.

Sob o ambiente político e o arco de alianças que sustentaram o regime de 1964 é que se instalam as mudanças institucionais desenhadas pelo Programa de Ação Econômica do Governo (doravante, PAEG) ${ }^{31}$, dentre as quais se inseririam as medidas da reforma tributária que se completaria definitivamente em 1967. Entre as reformas

\footnotetext{
${ }^{11}$ Uma descrição detalhada do Programa de Ação Econômica do Governo (PAEG) pode ser obtida no link http://www.fgv.br/Cpdoc/Acervo/dicionarios/verbete-tematico/programa-de-acao-economica-do-governopaeg, que permite o acesso ao consagrado acervo do CP-DOC da Fundação Getúlio Vargas (FGV). O documento original do PAEG é o seguinte: PAEG - Programa de Ação Econômica do Governo 1964-1966 (PAEG, 1967). Documentos EPEA - no 1, Rio de Janeiro: 1964. Trabalhos clássicos sobre o PAEG elaborados por André Lara Resende $(1982,1990)$ também merecem ser consultados.
} 
estruturais implementadas junto ao PAEG, destacam-se as reformas trabalhista, a financeira ${ }^{32}$ e a tributária33.

O mercado de trabalho também sofreu alterações importantes. A estabilidade no emprego para funcionários que trabalhassem na mesma empresa há mais de 10 anos foi substituída pelo FGTS (Fundo de Garantia por Tempo de Serviço). A política salarial, para conter surtos inflacionários, fez o salário real perder poder de compra. A queda no poder de barganha dos sindicatos com os empregadores fez com que o número de horas semanais trabalhadas aumentasse nas capitais, e, a partir de 1968, observou-se um crescimento na economia e redução do desemprego (SINGER, 1976) - mas com perfil distributivo crescentemente desigual, conforme mencionado na primeira parte deste artigo. Tais medidas se inserem em um amplo conjunto de mudanças na regulação das relações de trabalho que acabariam promovendo a piora do perfil distributivo. Ademais, a recessão provocada pelo manejo das variáveis-chave da política econômica implementada entre 1964 e 1966, já após um relativamente longo período recessivo (entre 1961 e 1964), gerou falência em diversas empresas de médio e pequeno portes, promovendo concentração em diversos mercados, ampliando as características oligopolistas dos mesmos e reforçando a concentração funcional da renda. O regime militar, ao adotar diversas medidas de caráter fiscal e tributário, beneficiando empresas de grande porte, acabaria amplificando as características de um padrão de consumo baseado na concentração da renda (OLIVEIRA, 1981). Singer (1976) destaca o papel que esse ambiente concorrencial teve para a arrecadação tributária, ressaltando que, quanto mais oligopolizado for um determinado setor, maior a possibilidade de repassar o aumento dos custos ao consumidor e, portanto, menor a probabilidade de sonegação fiscal. Também a fiscalização é mais fácil nessa situação, ao invés de um grande número de pequenas empresas.

O objetivo central dessa reforma tributária foi organizar o sistema tributário brasileiro e dar ao Estado condições de intervir mais fortemente no processo de

\footnotetext{
${ }^{32}$ A reforma financeira, apesar de sua evidente importância, não é objeto de análise neste estudo. Para maiores detalhes, ver: Tavares (1983). E, para os efeitos dessa e das outras reformas estruturais sobre o perfil distributivo, ver: Mattos, Bastos e Barone (2018).

33 Para maiores detalhes a respeito dessas reformas estruturais e seus efeitos distributivos, consultar: Mattos, Bastos e Barone (2018). A respeito dos argumentos que fizeram parte do debate sobre a trajetória do perfil distributivo nos anos do "milagre econômico", ver: Barone, Bastos e Mattos (2017).
} 
desenvolvimento econômico do país. Assim, o governo poderia aumentar sua capacidade de gastos e escolher quais setores favorecer através de isenções tributárias. Importante ressaltar que, com o governo centralizado, as decisões de investimento e estratégias de desenvolvimento também ficaram centralizadas - e poderiam ser moldadas ao perfil de acumulação capitalista que se desejava implementar.

O principal objetivo, portanto, era racionalizar o sistema tributário, adequando-o à nova economia industrial - construída desde a década de 1930 - e à urbanização crescente do país. O novo sistema tributário passou a ser interligado em âmbito econômico e jurídico, diferentemente do anterior, que contava com sistemas autônomos federal, estaduais e municipais. Agora, cabia à Constituição Federal e ao Código Tributário Nacional (CTN) definir competências e capacidade tributária para cada ente federativo. 34

Concomitante a isso, houve a promulgação da Constituição de $1967^{35}$ e a criação da Secretaria da Receita Federal em 1968, regulamentando e modernizando a operacionalização e fiscalização da arrecadação tributária. Como o Brasil estava sob regime autoritário, conflitos e pressões políticas foram mitigados, "facilitando" as mudanças no modelo tributário existente. Em linhas gerais, a Reforma de 1967 criou um sistema tributário que reduziu as distorções de mercado, organizou e definiu a cobrança e fiscalização dos tributos. A tributação passou a incidir sobre base econômica - fato gerador - e não apenas sobre definições jurídicas, como anteriormente, com a Constituição de $1946^{36}$.

34 O CTN (BRASIL, 1967) regulamentou três tipos de tributos: impostos, taxas e contribuições de melhoria. De acordo com o art. 16 do CTN, imposto é o tributo cuja obrigação tem por fato gerador uma situação independente de qualquer atividade estatal específica, relativa ao contribuinte. Os art. 77 a 80 do CTN definem as taxas como cobranças específicas e divisíveis, que apresentam contrapartida e contribuintes particulares. Finalmente, o art. 81 do CTN define as contribuições de melhoria, que podem ser cobradas para financiar obras públicas que gerem, obrigatoriamente, valorização imobiliária.

35 Na verdade, o CTN foi promulgado em 1966, mas como a constituição Federal de 1967 o recepcionou, convencionou-se chamar de Reforma Tributária de 1967 e CTN de 1967.

${ }^{36}$ As principais medidas da Reforma de 1967 foram: reunião dos impostos de transmissão intervivos e causa-mortis no imposto de transmissão de bens imóveis; criação do Imposto sobre Produto Industrializado (IPI) em substituição ao Imposto sobre Consumo, ambos de competência federal; extinção do Imposto do Selo e criação do Imposto sobre Operações de Crédito, Câmbio, Seguros, Títulos e Valores Mobiliários (IOF), de competência da União; criação do Imposto sobre Circulação de Mercadorias (ICM) em substituição ao Imposto sobre Vendas e Consignações (IVC), ambos de competência estadual; criação do Imposto sobre Serviços (ISS), de competência municipal; transferência para a União do Imposto de Exportação, antes administrado pelos estados; transferência para a União do Imposto Territorial Rural, anteriormente de competência municipal; instituição de tributos especiais sobre combustíveis, 
É importante notar que o Brasil foi um dos primeiros países a substituir o imposto em cascata pelo imposto sobre valor agregado, utilizando o conceito econômico como fato gerador para incidência tributária. Outro ponto que merece destaque na Reforma de 1967 foi a limitação ao poder de tributar dos estados e a redução das transferências (OLIVEIRA, 1981).

Assim, a finalidade do sistema tributário foi alcançar o equilíbrio orçamentário e promover o crescimento econômico por meio de incentivos fiscais que permitissem acumulação de capital. Os tributos foram utilizados como instrumento de política econômica, favorecendo uma pequena elite e deixando de lado o princípio de equidade. Com isso, consolidou-se o regime de acumulação do governo militar baseado na concentração de renda e riqueza com exclusão social, o que se deveu, em grande parte, à mudança no perfil da arrecadação, em favor da esfera federal e dos tributos indiretos, que oneram principalmente os mais pobres, em detrimento de tributos diretos, que incidem sobre a renda e a propriedade.

A carga tributária brasileira aumentou de $20 \%$ para $25 \%$ do PIB com as mudanças de 1967, sendo a maior parte de tributos federais. Com o fim do "milagre econômico" em 1973, o sistema tributário começou a apresentar falhas. Devido às suas características altamente regressivas, a arrecadação se enfraqueceu muito rapidamente com a queda no ritmo do crescimento e acentuou a desigualdade brasileira. Nas palavras de Belluzzo :

a reforma tributária foi guiada pelo critério de estimular a poupança, na suposição de que dela dependia o crescimento econômico 'sadio'. O resultado foi a complacência para com as rendas do capital e a sobrecarga contra os rendimentos do trabalho, gerando uma das mais iníquas sistemáticas tributárias do mundo capitalista (BELLUZZO, (1981, p. II).

Assim, ao incentivar um padrão de acumulação excludente, o sistema tributário mostrou um viés regressivo e elitista ao privilegiar favores tributários para parcelas do setor privado de maior poder econômico ou político, em uma sociedade já historicamente desigual. A regressividade não se manifestava apenas pelo lado da arrecadação, mas 
também do lado do gasto ${ }^{37}$. O crescimento econômico foi priorizado em detrimento da questão social, debilitando as necessidades crescentes de gastos em saúde e educação, em contexto de acelerada urbanização e aumento da renda média da população (MATTOS, BASTOS e BARONE, 2018; OLIVEIRA, 1981;). Dessa maneira, à desigualdade econômica gerada pelo mercado de trabalho somavam-se elementos relacionados ao sistema tributário de estrutura regressiva ${ }^{38}$.

Com o fim do regime militar e a restauração do processo democrático, uma nova Constituição foi elaborada e promulgada em 1988. Ainda que o objetivo primordial da nova Carta Magna não fosse alterar o sistema tributário, ela trouxe importantes modificações ao modelo de tributação nacional. A Constituição Federal de 1988 recepcionou os tributos do CTN e incluiu dois novos: o empréstimo compulsório e as contribuições especiais 39 .

No que diz respeito às finanças públicas, a nova constituição estabelecia maior autonomia fiscal aos estados e municípios, aumento dos repasses da União e desconcentração dos recursos tributários. Ou seja, visava reduzir a centralização acentuada pelo regime autoritário, restringindo a possibilidade da União em conceder isenções para tributos estaduais e municipais, o que antes era plenamente permitido. Agora, cada estado poderia fixar sua própria alíquota no imposto sobre o consumo, o

37 Trabalhos importantes de Mahon (2009, 2011) confirmam este aspecto da regressividade fiscal e tributária nos países da América Latina.

${ }^{38}$ Oliveira (1981) também ressalta o fato de que, do ponto de vista dos gastos públicos, a postura do governo na época (favorecido pela institucionalidade criada pelas reformas do PAEG) aprofundava o caráter desigual da sociedade brasileira. As seguintes palavras são esclarecedoras: "os gastos com a infraestrutura econômica e serviços mantiveram-se elevados durante todo o período, tendo atingido a média de $24 \%$ dos Gastos Federais entre 64/66, 23,7\% entre 67/69 e 18\% entre 70/73. Já os gastos com bemestar social se apresentaram declinantes: $4,8 \%$ para $64 / 66$, $4 \%$ para $67 / 69$ e tão somente $2 \%$ entre $70 / 73$, enquanto Defesa e Segurança aumentaram de $17,9 \%$ para $24,1 \%$ e $22,8 \%$ nos mesmos períodos" (OLIVEIRA, 1981, p. 104).

39 Pelo art. 148, fica estabelecido que a União poderá "instituir, mediante lei complementar, empréstimo compulsório para cobrir despesas extraordinárias por motivos de calamidade, guerra ou investimento público de caráter urgente" (BRASIL, [2016]). A lei deve instituir como e quando será a devolução desse "empréstimo" à população. O art. 149 define que "Compete exclusivamente à União instituir contribuições sociais, de intervenção no domínio econômico e de interesse das categorias profissionais ou econômicas, como instrumento de sua atuação nas respectivas áreas" (BRASIL, 1988). Ou seja, a União poderá instituir contribuições para-fiscais, delegando o trabalho de arrecadar e fiscalizar a outro ente da federação ou, até mesmo, às entidades privadas. Por exemplo, a contribuição paga ao CORECON e outros órgãos profissionais. A contribuição de iluminação pública é um exemplo quando a tarefa de arrecadar é repassada a entidades privadas, no caso do Rio de Janeiro, à concessionária de energia Light. 
ICMS. Ao incluir o S (serviços de transporte, telecomunicação, energia elétrica e combustível) ampliou-se a base de incidência do tributo, que teve sua participação na carga tributária elevada. O ICMS é um dos impostos que sofrem as maiores críticas por parte dos especialistas tributários já que ele é regressivo e não centralizado, podendo gerar guerra fiscal entre os estados (VARSANO, 1996).

O regime democrático também privilegiou a questão social que, durante a Ditadura, perdeu prioridade para a questão econômica. Portanto, a nova Constituição aumentou os gastos públicos e promoveu a descentralização das receitas. Para combater os desequilíbrios fiscais e perdas de recursos, o governo adotou algumas medidas compensatórias que pioraram a qualidade do sistema tributário.

Houve, assim, a instituição de novos tributos e elevação de alíquotas daqueles que não têm repasse para estados e municípios: (i) Criação da Contribuição Social sobre Lucro Líquido (CSLL) em 1989; (ii) criação do Imposto provisório sobre Movimentações Financeiras (IPMF40) em 1993; (iii) aumento da alíquota da Cofins e do IOF em 1990. Tanto a CSLL como o IPMF são tributos cumulativos, ou seja, em cascata. O sistema tributário estava, então, regredindo às falhas que a Reforma de 1967 eliminara. Demais contribuições sociais foram instituídas enquanto impostos já estabelecidos, como o IPI e o IR, com ampla base de incidência e igual potencial de arrecadação, foram pouco utilizados, por terem suas receitas compartilhadas.

Em 1995, o IR sofreu mudanças, como a extinção da correção monetária; aumento da alíquota máxima do IRPF de $25 \%$ para 27,5\%; e diversas alterações na legislação do imposto de renda incidente sobre as operações financeiras, como a isenção da tributação sobre lucros e dividendos. As frequentes alterações no sistema tributário o tornaram ineficiente, causando distorções nos mercados, sem resolver a origem do problema: o desequilíbrio nas competências de arrecadar e dos gastos. O resultado de todas as mudanças arroladas acima é visível no gráfico IV. Percebe-se que a carga tributária bruta brasileira atingiu, em 2013, seu maior valor, de 36\%, do PIB, depois de ter mudado de patamares em diversos momentos desde do início da série histórica obtida nas Contas Nacionais (1947).

\footnotetext{
40 Posteriormente transformada na atualmente extinta CPMF.
} 
Gráfico IV - Carga Tributária Bruta Brasileira 1947 - 2017

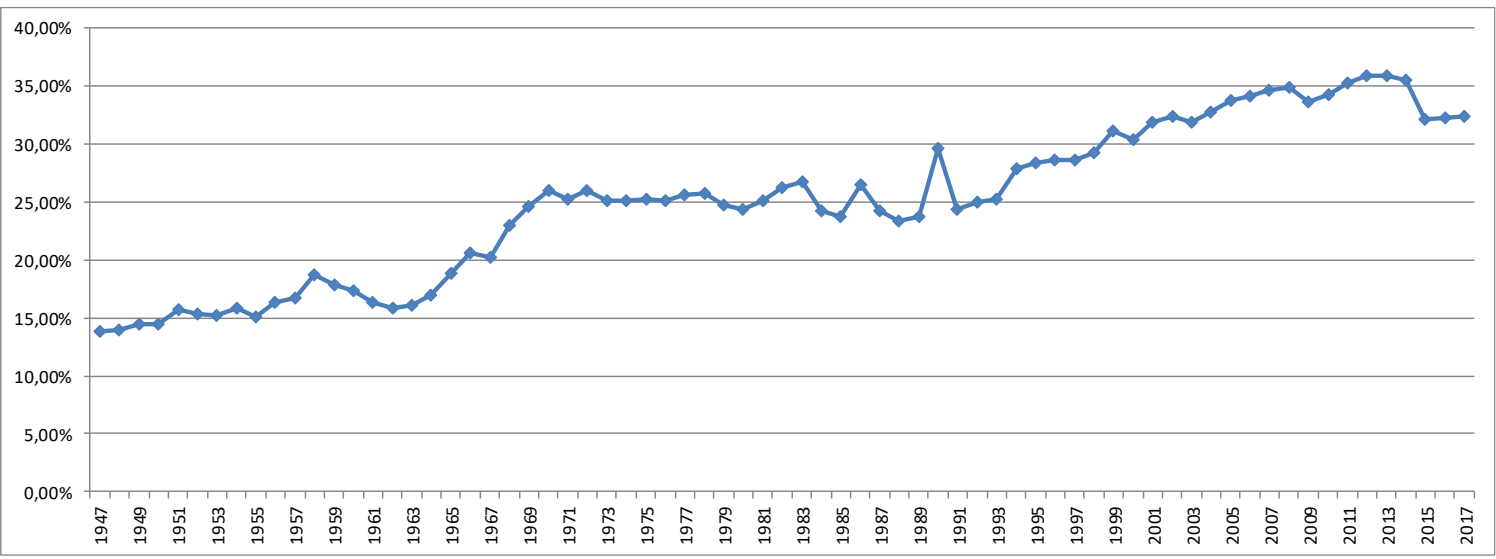

Fonte: elaboração própria a partir das Contas Nacionais do IBGE e da Receita Federal.

O gráfico acima mostra claramente a evolução da CTB no Brasil. É possível perceber as mudanças de patamares: primeiro em 15\%, desde quando existe a série histórica, atingindo $20 \%$ em 1966, saltando para 25\% a partir de quando se consolida a Reforma Tributária de 1967, ao aumentar a base de incidência e criar novos tributos ${ }^{41}$, mantendo-se nesse patamar até o Plano Real. O ponto fora da curva no início da década de 1990 se deve ao Plano Collor, que, com medidas extremas de curto prazo, conseguiu um aumento da arrecadação nas três esferas de governo, reduzindo o efeito Tanzi ${ }^{42}$. A queda no final da série é devido ao desaquecimento da economia nos anos recentes.

O Plano Real estabilizou a economia brasileira e deu base a novas incidências como a "reforma" do IR em 1995. O mesmo também conteve a inflação e a economia apresentou um modesto crescimento inicial, o que propiciou elevação da receita. Em 2009, porém, devido à crise internacional e às isenções praticadas (IPI para automóveis, por exemplo), observa-se uma pequena queda na arrecadação tributária brasileira. Já em 2010, este valor se recupera, junto ao crescimento da economia, atingindo, em 2013, seu maior valor.

O gráfico V ilustra a composição da carga tributária bruta, demonstrando o caráter regressivo da tributação brasileira. Os tributos diretos, que em tese podem ser

\footnotetext{
${ }^{41}$ A introdução dos impostos por valor adicionado, incidentes sobre uma ampla gama de atividades econômicas como o IPI, do ICM e do ISS, a ampliação do Imposto de Renda e o aumento de alíquotas de diversos impostos, em seu conjunto, se somaram para promover uma significativa ampliação da base tributária e, por conseguinte, aumento da carga tributária bruta.

$4^{2} \mathrm{O}$ efeito Tanzi decorre da defasagem entre o fato gerador e a arrecadação do tributo. Com alta inflação, o governo perde arrecadação real.
} 
progressivos, têm relativamente baixa representatividade na carga total - notadamente quando se compara com outros países. Quase 50\% da carga tributária é composta por tributos sobre o consumo (ou seja, tributos indiretos, como o ICMS), enquanto o imposto sobre a renda e a propriedade representam, somados, apenas $24 \%$ da CTB.

Gráfico V - Composição da Carga Tributária Bruta por tipo de tributo - 2017

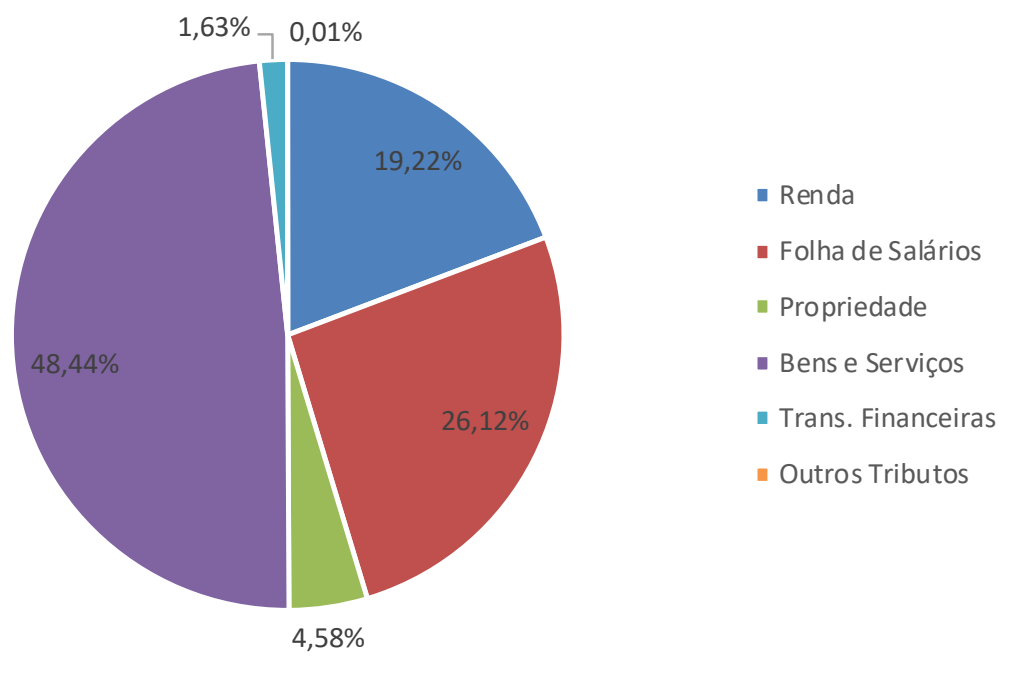

Fonte: Adaptado de Brasil (2018).

Deve-se ponderar, porém, que mesmo tributos diretos que poderiam ser progressivos, mas têm alíquotas únicas, como o IPTU e o IPVA ${ }^{43}$, acabam se tornando regressivos ao onerarem mais as classes sociais mais baixas. Sobre o IPTU, vale citar Payeras (2010), que lembra que esse imposto representa 1,62\% no estrato de renda de $R \$$ 0 - $R \$ 400,1,55 \%$ de $R \$ 400-R \$ 600$ e apenas $1,05 \%$ para quem ganha mais de $R \$ 6.000$. Em compensação, O IR se mostra extremamente progressivo representando $4,12 \%$ para rendas acima de $R \$ 6.000$ e $0 \%$ para os estratos de rendas de $R \$ 0-R \$ 400$ e $R \$ 400-R \$$ 600. O IR, então, é progressivo, contribuindo para redução da desigualdade enquanto o IPTU se mostra regressivo, contribuindo para o aumento da desigualdade.

No que tange aos tributos indiretos, Payeras (2010) estimou que a carga indireta é de $21 \%$ para famílias com renda de até $\mathrm{R} \$ 400 ; 17,5 \%$ para famílias com renda entre $\mathrm{R} \$ 400$ -

43 IPTU: imposto sobre território urbano. Pode ser progressivo, mas na maioria das vezes tem alíquota única, como no Rio de Janeiro, onde é de 1,2\% para imóveis residenciais. IPVA: imposto sobre propriedade veicular. No estado do Rio de Janeiro, por exemplo, tem alíquota única de $4 \%$. 
$\mathrm{R} \$$ 600; e de 10\% para rendas acima de $\mathrm{R} \$$ 6.000. Essa característica que faz com que a carga tributária indireta seja considerada regressiva ${ }^{44}$. No mesmo sentido, Zockun (2005) estima que os brasileiros com até dois salários mínimos pagam 48,8\% de sua renda com tributos, enquanto os que recebem mais de trinta salários mínimos pagam $26 \%$.

O ICMS, de competência estadual, é o tributo com maior peso na carga tributária indireta das famílias e, como os gastos com alimentos e habitação representam a maior parte da renda dos mais pobres do que dos ricos, o padrão de consumo das famílias mais pobres está sendo mais tributado do que o padrão de consumo das famílias mais ricas. $O$ ICMS chega a pesar 11\% na renda de famílias de $\mathrm{R} \$ 0$ - $\mathrm{R} \$ 400 ; 9 \%$ para rendas entre $\mathrm{R} \$ 400$ - R\$600; e 6\% para rendas acima de $R \$ 6.000$ (PAYERAS, 2010).

A carga indireta sobre alimentação e habitação representa mais de $11 \%$ da renda de quem recebe até $\mathrm{R} \$ 400$, e menos de $3 \%$ para rendas acima de $\mathrm{R} \$ 600$. Os tributos indiretos sobre alimentos e habitação acabam onerando mais os mais pobres. Em compensação, a carga indireta sobre o transporte se mostra progressiva, representando $1,5 \%$ na renda dos mais pobres e $4,77 \%$ para a classe mais alta (PAYERAS, 2010).

Kerstenetzky (2012), utilizando dados de Lustig (2011), mostra como o índice de Gini da renda de mercado $(A)^{45}$ é pouco alterado após a incidência de tributos diretos e de contribuições sociais - resultando na renda de mercado líquida (B). Na definição de renda disponível (C), leva-se em conta o efeito das transferências. Nesse caso, há uma redução pequena no índice de Gini, denotando o modesto efeito das transferências sobre a desigualdade. A seguir, quando se calcula o Gini após a incidência dos tributos indiretos e subsídios, a chamada renda de pós-fisco (D), o Gini praticamente não se altera.

\section{Quadro I}

\begin{tabular}{|cccc|}
\hline $\begin{array}{c}\text { Renda de } \\
\text { mercado (A) }\end{array}$ & $\begin{array}{c}\text { Renda de } \\
\text { mercado } \\
\text { líquida (B) }\end{array}$ & $\begin{array}{c}\text { Renda } \\
\text { Disponível (C) }\end{array}$ & $\begin{array}{c}\text { Pós - Fisco } \\
\text { (D) }\end{array}$ \\
\hline 0,572 & 0,560 & 0,546 & 0,545 \\
\hline
\end{tabular}

Fonte: Adaptado de Kerstenetzky (2012) e Lustig (2011).

44 IPEA (2009a) e IPEA (2009 b) são estudos que confirmam essa avaliação, com base em outras maneiras de organização dos dados.

${ }^{45} \mathrm{~A}$ renda de mercado é formada pelos rendimentos auferidos no mercado de trabalho além de aposentadorias e pensões. 
Desta forma, pelos dados do quadro I, percebe-se a modesta influência de tributos e transferências sobre a já mencionada desigualdade gerada no mercado de trabalho notadamente quando se compara com outros países, conforme mostram os dados da tabela $1^{46}$.

Tabela 1

INDICES DE GINI EM PAÍSES SELECIONADOS

ANTES E DEPOIS DA COBRANÇA DE IMPOSTOS

\begin{tabular}{|c|c|c|c|}
\hline PAÍSES & $\begin{array}{l}\text { antes dos } \\
\text { impostos }\end{array}$ & $\begin{array}{l}\text { depois dos } \\
\text { impostos }\end{array}$ & $\begin{array}{l}\text { \% da redução do Gini devido a } \\
\text { impostos e transferências }\end{array}$ \\
\hline Brasil & 0,598 & 0,571 & $-4,50$ \\
\hline EUA & 0,57 & 0,42 & $-26,3$ \\
\hline Israel & 0,58 & 0,41 & $-29,3$ \\
\hline Reino Unido & 0,63 & 0,41 & $-34,9$ \\
\hline Canadá & 0,55 & 0,38 & $-30,9$ \\
\hline Grécia & 0,60 & 0,38 & $-36,7$ \\
\hline Espanha & 0,57 & 0,38 & $-33,3$ \\
\hline Austrália & 0,55 & 0,38 & $-30,9$ \\
\hline Noruega & 0,57 & 0,38 & $-33,3$ \\
\hline Coréia do Sul & 0,44 & 0,37 & $-15,9$ \\
\hline Polônia & 0,65 & 0,36 & $-44,6$ \\
\hline Alemanha & 0,60 & 0,36 & $-40,0$ \\
\hline Holanda & 0,57 & 0,33 & $-42,1$ \\
\hline Suécia & 0,57 & 0,33 & $-42,1$ \\
\hline Dinamarca & 0,56 & 0,33 & $-41,1$ \\
\hline Suíça & 0,47 & 0,31 & $-34,0$ \\
\hline
\end{tabular}

Fonte: IPEA (2011 b); demais países: dados de Luxembourg Income Study (2018). Elaboração própria.

(*) Dados do Brasil referem-se a 2008/9 (referenciados pela POF); dados dos demais países referemse a 2012.

\footnotetext{
${ }^{46}$ Os dados da tabela 1, referentes ao Brasil, não são exatamente iguais aos demonstrados no quadro I, pois existe uma pequena diferença metodológica entre eles. Deve-se ressaltar, entretanto, que em ambos os casos a diferença promovida pela incidência de impostos e transferências sobre a renda pessoal é quase igual.
} 
Os dados exibidos pela tabela 1 evidenciam a peculiaridade brasileira, comparandoo com países desenvolvidos, onde as políticas sociais são mais abrangentes e, portanto, corrigem de forma significativa as desigualdades geradas na renda bruta (a qual resulta do funcionamento do mercado de trabalho). Essa forma de organizar os dados e de exibir indicadores sintéticos para renda bruta e também para renda líquida, comparando o efeito das políticas sociais, é bastante encontradiço na literatura internacional, justamente porque são países que constituíram há décadas importantes sistemas de Estado de Bem Estar Social (KERSTENETZKY, 2012). Na verdade, os termos "antes e depois dos impostos" ("pre-tax and after-tax") significam algo mais abrangente do que parecem, pois, além de levarem em conta a incidência de tributos, consideram também as transferências sociais feitas em favor dos mais pobres, segundo as regras específicas de cada caso nacional.

A especificidade brasileira é fato estudado na literatura internacional - e não exclusivo do país, sendo também muito comum em outros países da América Latina. Referimo-nos ao fato de a estrutura tributária e as políticas sociais não atuarem na redução da desigualdade como deveriam, dado o elevado nível de desigualdade na renda primária brasileira47. Esse quadro espelha um aspecto da multidimensionalidade da desigualdade brasileira e de seu aspecto estrutural e histórico, fincado em bases institucionais concretas e historicamente determinadas. Trata-se, neste aspecto, do que Lindert (1991, p. 226) chama de "paradoxo de Robin Hood às avessas", ou seja, reside no fato de que justamente nos países em que o mercado de trabalho e o setor privado geram as desigualdades mais significativas, as políticas tributária e fiscal menos atuam no sentido de "corrigir" ou pelo menos atenuar as desigualdades da renda primária. Ou seja, a existência do chamado "paradoxo de Robin Hood às avessas" nos faz refletir para o fato de que os agentes estruturais/institucionais ${ }^{48}$ que levam à geração das desigualdades

\footnotetext{
47 Renda primária é definida aqui como sendo a renda gerada pelo mercado privado. Pode ser considerada também como a renda bruta, ou seja, a renda sem levar em conta a incidência de impostos ou de transferências.

${ }^{48}$ Muitos outros fatores institucionais poderiam ser colocados em tela aqui, mas, por falta de espaço, esta discussão ficaria para outro momento. Entre estes fatores, poderíamos elencar o papel dos meios de comunicação, o formato das disputas eleitorais e as práticas dos mandatos parlamentares, o funcionamento da Justiça etc. Uma moderna literatura nas áreas de Sociologia e de Ciência Política, por exemplo, tem discutido como a Democracia, nos tempos atuais (em contraste, por exemplo, com o que acontecia nos
} 
de renda primária ("pre-tax") também atuam, de variadas maneiras, no desenho das políticas sociais e políticas públicas em geral - o que revela a complexidade do fenômeno da desigualdade ${ }^{49}$.

Por fim, alguns comentários sobre as rendas muito altas, que na literatura internacional estão consagradas como o debate sobre o $1 \%$ e $0,1 \%$ mais ricos ${ }^{50}$. No caso brasileiro, deve-se registrar que apesar de a desigualdade ter diminuído ${ }^{51}$ nos últimos anos, como revelado pela evolução do índice de Gini, explicitado na primeira parte deste artigo, a concentração de renda no topo da distribuição vem aumentando, como mostra o gráfico VI. Tal cenário evidencia a necessidade de se estudar mais ao fundo a trajetória recente do perfil distributivo brasileiro. Embora sejam inegáveis os progressos medidos pelos indicadores mais tradicionalmente utilizados para medir a desigualdade na distribuição pessoal da renda, é preciso registrar a importância de se incluir os dados de renda não exclusivamente provenientes do trabalho.

tempos da consolidação do Welfare State, em países europeus, ou nas décadas que se seguiram à implementação do New Deal, nos EUA) é afetada pela e também promove a desigualdade econômica nos países desenvolvidos. Sobre o caso dos EUA, recomenda-se a leitura, pelo menos, de: Hacker e Pierson (2010), AMERICAN... (2004) e Bonica, McCarthy, Poole e Rosenthal (2013). Para o caso específico da América Latina, ver Coatsworth (2008).

49 A necessidade de se debruçar sobre esse ponto específico do debate distributivo já vinha sendo apregoada por Lindert (1991, p. 226) no início da última década do século passado: "Thus far the subject has been inequality in pre-fisc income. I predict, however, that the most active research frontier in the history of income inequality will be the task of explaining changes in the degree of progressive income redistribution through government and its relationship to the level of pre-fisc inequality". Em tradução livre: "Até agora, o tema tem sido a desigualdade de renda bruta. Eu prevejo, porém, que a fronteira de pesquisa mais ativa na história da desigualdade econômica seja a tarefa de explicar mudanças no grau da progressividade da distribuição da renda através das políticas públicas e sua relação com a desigualdade de renda bruta, ou seja, a renda antes da incidência dos impostos".

${ }^{50}$ Sobre a importância de se estudar e de se avaliar as rendas do topo e seus efeitos sobre a desigualdade total em uma sociedade capitalista - notadamente no que se refere às formas de funcionamento do capitalismo nos anos mais recentes, ver, pelo menos: Piketty (2014), Atkinson e Piketty (2007), Dedecca (2009, 2010), Dedecca, Jungbluth e Trovão (2008).

${ }^{51}$ Notadamente quando medida segundo os indicadores de renda do trabalho, captados em pesquisas domiciliares. 
Gráfico VI - Percentual da renda total apropriado pelo 1\% e 0,1\% dos mais ricos. Brasil, 2001-2015

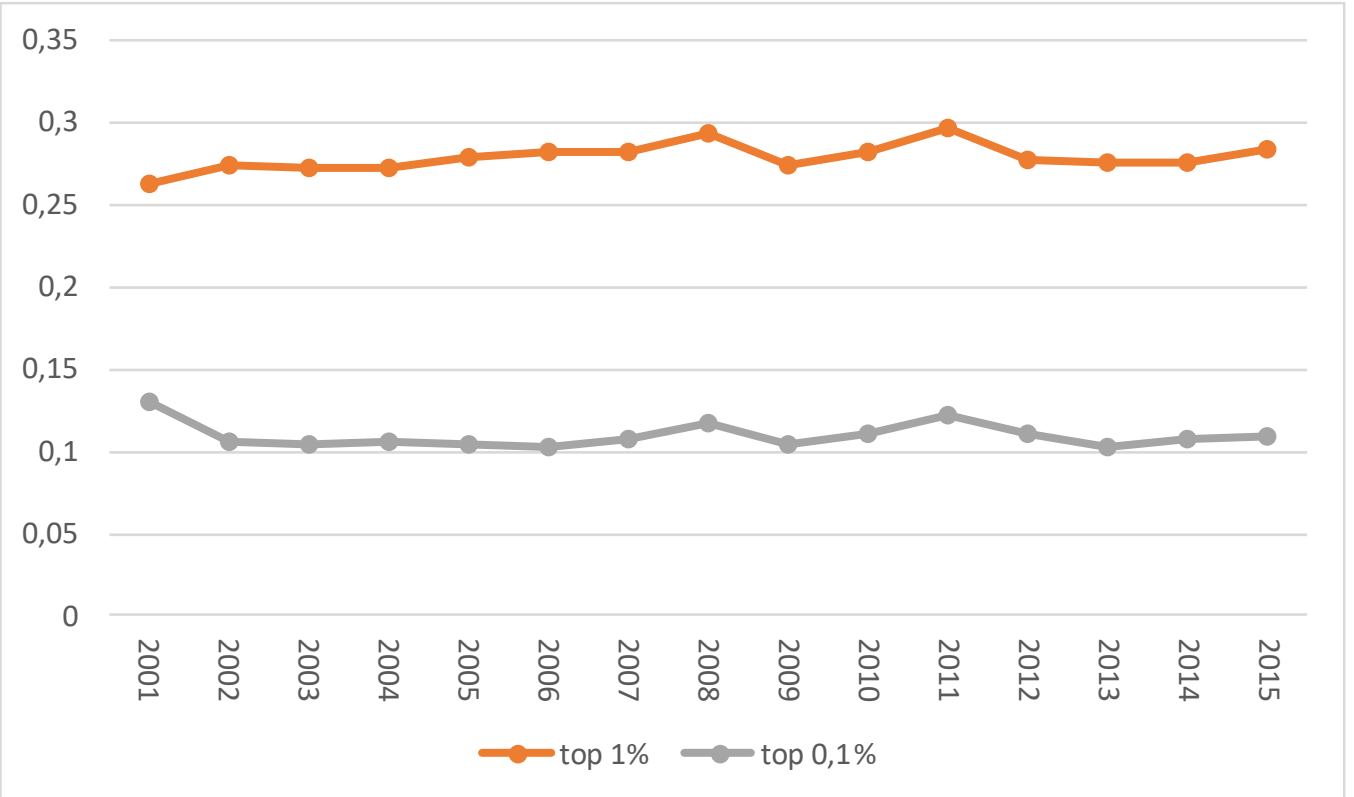

Fonte: Adaptado de MORGAN (2017).

O gráfico $\mathrm{VI}$, compilado com dados da Receita Federal, mostra o percentual de renda auferido pelos mais ricos nos últimos anos no Brasil. O 1\% mais rico concentra quase $30 \%$ de toda a renda nacional, tendo revelado um modesto crescimento da renda apropriada, comparando-se os anos extremos do gráfico (2001 e 2015); enquanto isso, o $0,1 \%$ mais rico concentra pouco mais de $10 \%$ de toda a renda nacional. Este estrato revelou certa estabilidade na apropriação da renda nacional entre 2002 e 2015. Ou seja, 30\% de toda a renda do país está concentrada nas mãos de $1 \%$ da população, sendo que a décima parte do percentil mais rico (ou seja, o 0,1\%) detém um terço de toda a renda apropriada pelo primeiro percentil (10\% contra 30\%).

Deve-se ainda sublinhar, de todo modo, que, apesar da maior precisão dos dados tributários em comparação aos do mercado de trabalho, os registros tributários podem ainda estar subestimados, pois não levam em conta dados de Pessoas Jurídicas (PJ) no Imposto de Renda. Muitos trabalhadores autônomos que atuam como profissionais liberais (médicos, dentistas, advogados etc.) declaram imposto de renda como pessoa jurídica (PJ) a fim de pagar menos tributos, já que os lucros e dividendos não são tributados no Brasil. Consequência disso é que, de acordo com dados das declarações de IRPF (BRASIL, 2016), pode-se depreender que, quem ganha acima de 80 salários mínimos 
por mês tem $60 \%$ ou mais de sua renda não tributada. Assim, a tributação, que deveria cobrar mais de quem tem mais, acaba isentando justamente os mais ricos, causando distorções adicionais e tornando ainda mais regressiva a estrutura tributária. Tal peculiaridade da legislação brasileira, em não tributar lucros e dividendos no IRPF, foi introduzida na supracitada "reforma" de 1995.

A leitura de PIKETTY (2014), que argumenta que a desigualdade de riqueza é bem maior do que a desigualdade de renda (salários), inspira uma investigação mais acurada sob esse ponto de vista para o caso brasileiro. O quadro II apresenta estatísticas de Gini para renda e também para riqueza e fica claro como a riqueza (patrimônio) está muito mais concentrada do que a renda de mercado. $G_{R B}$ é definido como o índice de Gini da Renda Bruta no Brasil, ou seja, aquela antes da tributação e das transferências (renda de mercado) e $G_{R I}$ o índice de Gini da Riqueza total no Brasil.

Quadro II

Índice de Gini de renda e de riqueza - 2006, 2009 e 2012

$\begin{array}{ll}G_{R B}^{2006}=0,581 & G_{R I}^{2006}=0,860 \\ G_{R B}^{2009}=0,576 & G_{R I}^{2009}=0,850 \\ G_{R B}^{2012}=0,564 & G_{R I}^{2012}=0,849\end{array}$

Fonte: Castro (2014).

Com isso, pode-se concluir que não só a tributação sobre a renda, mas também sobre o patrimônio poderia ser mais expressiva a fim de reduzir a concentração no Brasil. É fácil perceber que só programas de transferências de renda não promovem melhorias substantivas no perfil distributivo em um país como o Brasil. Ademais, da quase neutralidade do sistema tributário, da carga tributária extremamente regressiva, nossos tributos diretos têm pouca representatividade na carga tributária total. 
O Imposto sobre Grandes Fortunas (IGF), previsto na Constituição Federal de 1988, e até hoje não implementado, poderia contribuir para diminuir a concentração de renda no topo da distribuição. Este tipo de tributo é cobrado efetivamente em diversos países no mundo todo, inclusive nossos vizinhos - Argentina, Uruguai e Colômbia - ou países de renda per capita menor do que a nossa, com destaque para o caso da Índia. Além do mais, diversos países tributam a riqueza de diferentes formas, incluindo na base de cálculo de seus tributos sobre a propriedade jatos, helicópteros e iates, os quais no Brasil não são tributados pelo IPVA ou por qualquer outro tributo no Brasil.

Assim, percebe-se que as mudanças tributárias ocorridas no período e a atual estrutura tributária certamente contribuíram para agravar a desigualdade de renda do Brasil.

\section{Conclusões}

Este artigo discutiu a evolução da desigualdade econômica brasileira desde meados do século $X X$ sob dois pontos de vista: em uma primeira parte, avaliando a desigualdade gerada pelo mercado de trabalho, e na segunda parte, buscando interpretar como a estrutura tributária, notadamente após 1967, afetou o perfil distributivo na economia brasileira. Trata-se de dois aspectos fundamentais, que se combinam para constituir uma das sociedades mais desiguais do mundo, em termos socioeconômicos e de distribuição de renda.

Na primeira parte, a análise conjunta de cada um dos três padrões de comportamento verificados no gráfico I e dos indicadores exibidos nos dois gráficos imediatamente seguintes, fornecem elementos importantes para avaliar a evolução da desigualdade econômica brasileira em perspectiva histórica, destacando como se alterou o perfil distributivo (medido por indicadores de renda auferidos no mercado de trabalho) desde a consolidação da industrialização pesada.

Uma questão que chama a atenção na primeira parte do estudo é a valorização expressiva ocorrida no salário mínimo real durante o período chamado nacionaldesenvolvimentismo. Não há dados organizados que permitam avaliar se naqueles anos 
houve melhoria do perfil distributivo. De todo modo, a literatura sobre o período ensina que nos anos 1950 ocorreu uma pronunciada transformação no padrão de consumo, ao lado de um processo de urbanização marcado pela ascensão de camadas médias assalariadas, em sua maior parte, e com ligação direta ou indireta com as transformações ocorridas no mercado de trabalho diante do processo de industrialização.

Durante esse período, apesar de suas contradições políticas e das recorrentes crises de balanço de pagamentos, foi possível construir uma aliança de classes em favor da transformação do capitalismo nacional. Para engendrar o padrão de acumulação capitalista daquele período, foi preciso criar pelo menos algum grau de fortalecimento do mercado interno, sendo que, para isso, o instrumento de recuperação do valor real do salário mínimo (conforme aconteceu, especialmente, sob o segundo governo Vargas e sob o Governo JK - ou seja, durante um breve e próspero período democrático ${ }^{52}$ ) teve papel decisivo. As desigualdades, porém, em suas causas mais estruturais, não foram eliminadas e nem mesmo diluídas, de tal forma que a sociedade brasileira adentrou os anos $1960^{53}$ sob um perfil distributivo extremamente desigual, bastando que a

52 Bresser-Pereira (2014) está entre os autores que ponderam, adequadamente, que não houve uma Democracia plena no período 1945-1964, uma vez que os analfabetos não tinham direito a voto (o que somente seria conquistado na Constituição de 1988 - a Constituição Cidadã, segundo o presidente daquela Assembleia Constituinte, o deputado paulista Ulisses Guimarães) e porque o PCB (Partido Comunista Brasileiro) foi declarado ilegal em 1947 e seus representantes eleitos tiveram seus mandatos cassados em 1948, em todas as esferas da Federação. Não obstante, o autor reconhece a relevância do mencionado período para diversos avanços democráticos, incluindo a conquista de Direitos Civis e Sociais. No que concerne ao que foi discutido neste artigo, vale também sublinhar ponderações que o clássico livro de Bielschowsky (2000) traz à discussão, destacando que a Democratização dos anos 40 e 50 abriu espaço para um debate sobre o desenvolvimento econômico e a necessidade de o Brasil se industrializar (o famoso “debate pioneiro" entre o economista liberal Eugênio Gudin e o empresário e professor Roberto Simonsen). Bielschowsky lembra que, naquele período, não houve um debate explícito acerca da evolução do perfil distributivo (pelo menos não como o debate que se instalaria a partir dos anos 60 ou, mais ainda, a partir da divulgação dos resultados do Censo de 1970, que permitiu avaliar a evolução do perfil distributivo dos anos 60 com dados e informações oficiais e abrangentes, conforme mostramos aqui). De todo modo, diversos aspectos do "debate pioneiro" acabariam, inevitavelmente, tocando em temas relacionados à distribuição da renda e da propriedade, ainda mais porque aquele momento de redemocratização levaria a uma discussão dos elementos constitutivos das relações entre capital e trabalho (Bielschowsky, 2000). Nas palavras do autor, referindo-se aos anos 40 e 50, "até o início dos anos 60, o debate econômico centrou-se na problemática do desenvolvimento das forças produtivas, deixando-se em plano secundário as questões mais diretamente sociais, como distribuição de renda e da propriedade" (Bielschowsky, 2000, p. 264). Por fim, vale o registro do autor, segundo o qual, a partir de meados dos anos 1950, instalou-se um debate que, nos anos seguintes, tomaria mais corpo e mais radicalização política: trata-se do debate sobre reforma agrária e propriedade da terra - o que não deixa de ser um tema relacionado à questão da distribuição da riqueza (e da renda).

53 Bastos (2014) apresenta uma descrição das dificuldades econômicas que a década de 1950 legou aos anos 
estagnação econômica ocorrida no início dos anos 1960 acirrasse rivalidades sociais e políticas latentes, levando a um desdobramento político dramático.

O regime inaugurado em 1964 moldou um padrão de acumulação excludente, para o qual a concentração da renda e da riqueza não representou entrave para o crescimento da economia, pelo menos durante o chamado Milagre Econômico. As reformas institucionais feitas pelo PAEG, o primeiro programa de governo, abriram espaço para que a desigualdade já existente na sociedade brasileira pudesse ser reforçada no sentido de impulsionar um padrão de consumo que repousava na demanda por bens e serviços de valores unitários relativamente altos, tendo em vista a renda média da sociedade brasileira. Para tanto, a política econômica, em seus diversos aspectos, promoveu a ampliação da desigualdade, quer seja pelas regras de definição da política salarial e da regulação do trabalho, quer seja pela política tributária regressiva, ou ainda através do padrão de gastos públicos em que às camadas mais altas da pirâmide distributiva eram destinados os maiores benefícios diretos ou indiretos, conforme mostraram os argumentos desenvolvidos na segunda parte do artigo.

A análise de indicadores de concentração (aqui, o índice de Gini) antes e depois da incidência de impostos e transferências revela os limites e os condicionantes para movimentos de melhoria do perfil distributivo brasileiro, explicitando o fato de que a complexa desigualdade brasileira não pode ser explicada apenas pelo funcionamento do mercado de trabalho.

O primeiro debate organizado sobre distribuição de renda na economia brasileira foi estimulado pelo contexto do Milagre Econômico do final dos anos 1960, meados dos anos 1970. Aquela realidade ensinou a todos que não basta haver crescimento econômico para que ocorresse melhoria do perfil distributivo. A complexidade estrutural da desigualdade brasileira exige uma combinação virtuosa de fatores econômicos e de elementos políticos que criem as condições para que determinadas coalizões de classes sociais atuem em favor do enfrentamento do problema da pobreza e do perfil distributivo altamente concentrado que caracteriza a sociedade brasileira. 
O que os indicadores reunidos neste artigo ensinam, antes de qualquer coisa, é que, sempre que houve descompromisso com a recuperação do valor real do salário mínimo e/ou dificuldades econômicas para promover seu aumento, o perfil distributivo só fez se deteriorar (mesmo, muitas vezes, já partindo de uma situação de significativa desigualdade). Mais do que isso, tanto as políticas de definição do valor real do salário mínimo, como as reformas promovidas na estrutura tributária chamam a atenção para aspectos políticos que afetam o perfil distributivo de uma sociedade capitalista como a brasileira.

Ademais, a complexidade da desigualdade brasileira exige que a mesma seja avaliada de uma maneira mais ampla do que a forma mais consagrada pela literatura - ou seja, através das rendas do trabalho ou destas somadas a outros rendimentos pessoais. É inegável que recentemente houve melhoria do perfil distributivo, quando o mesmo é medido pelos indicadores de distribuição pessoal da renda. Sob esse critério, teve papel decisivo a recuperação do valor real do salário mínimo ocorrida, de forma mais consistente, a partir de 2004/2005 até 2011 ou 2012, dependendo do indicador de desigualdade escolhido. A fragilidade dessa trajetória, porém, já se revela no fato de que bastaram quatro anos de desaceleração do crescimento econômico ${ }^{54}$, com índices de crescimento do PIB per capita menores do que os que haviam permitido a redução do índice de Gini ocorrido entre 2002 e 201055, para que a redução da desigualdade mostrasse também arrefecimento.

Este artigo incorporou um elemento adicional para retratar a complexa natureza da desigualdade econômica brasileira, ao avaliar os efeitos do sistema tributário sobre o perfil distributivo. Conclui que o sistema tributário brasileiro representa um fator gerador de distorção na desigualdade econômica, inicialmente gerada no âmbito do mercado de trabalho, contrastando com o que ocorre na maior parte dos países desenvolvidos, onde a incidência de impostos e de transferências sociais atenua as desigualdades produzidas pela exploração do trabalho. Ademais, procurou-se chamar a atenção, no âmbito do espaço disponível para a redação, para trabalhos recentes que demonstram que a

\footnotetext{
${ }^{54}$ Não faz parte do objetivo deste artigo discutir causas da desaceleração econômica ocorrida a partir de 2011.

55 Entre 2002 e 2010, o índice de Gini caiu quase 10\%, enquanto entre 2010 e 2014 caiu menos de 1\%, estagnandose em 2015 e 2016.
} 
desigualdade econômica brasileira é complexa e comporta diversas formas de interpretação e de medição. A redução recente da desigualdade medida pelo índice de Gini dos rendimentos do trabalho lança um desafio aos pesquisadores brasileiros e estrangeiros sobre o tema, não somente pelo evento recente ser pouco encontradiço na história econômica do Brasil, mas também pelo fato de que a desigualdade em si poderia, e deveria, ser interpretada de forma cada vez mais abrangente e multidimensional.

A experiência histórica brasileira (e de outros países da América Latina) mostrou que melhorias de perfil distributivo somente ocorrem quando se têm, concomitantemente, diversos fatores: estabilidade política; estabilidade democrática, notadamente permitindo uma união de classes sociais, formal ou informalmente (o que pode ser feito via coalizão de partidos políticos); aumentos reais do salário mínimo; ampliação de políticas sociais e crescimento econômico, com melhoria dos indicadores de emprego; estrutura tributária adequada. Esses são os grandes desafios que se colocam atualmente para a sociedade brasileira.

\section{Referências}

ALMEIDA, Gelsom Rozentino. A política econômica do governo Figueiredo (1979-1985): choque e ajuste externo, desequilíbrio interno, ortodoxia, a classe trabalhadora e a oposição do PT. In: MARTINS, Mônica de Souza Nunes; CAMPOS, Pedro Henrique Pedreira; BRANDÃO, Rafael Vaz da Motta (Org.). Política econômica nos anos de chumbo. Rio de Janeiro: Consequência, 2018. p. 285-317.

AMERICAN POLITICAL SCIENCE ASSOCIATION. American democracy in an age of rising inequality. [S.I.]: Task Force on Inequality and American Democracy. 2004.

ATKINSON, Anthony; PIKETTY, Thomas (Org.). Top incomes over the Twentieth Century. Oxford: OUP Oxford, 2007.

ATKINSON, Anthony. Measuring top incomes: methodological issues. In: ATKINSON, Anthony; PIKETTY, Thomas (Org.). Top incomes over the Twentieth Century. Oxford: OUP Oxford, 2007. p. 1-35. 
BALTAR, Paulo Eduardo de Andrade. Estrutura econômica e emprego urbano na década de 1990. In: PRONI, Marcelo; HENRIQUE, Wilnês (Org.). Trabalho, mercado e sociedade: o Brasil nos anos 90. São Paulo: UNESP, 2003. p. 107-152.

BALTAR, Paulo Eduardo de Andrade; DEDECCA, Cláudio. Emprego e salários nos anos 60 e 70. Cadernos do CESIT, Campinas (SP), n. 12, p. 1-21, set. 1992.

BARONE, Ricardo; BASTOS, Pedro Paulo Zahluth; MATTOS, Fernando Augusto Mansor. Capital humano ou capitalismo selvagem? Um balanço da controvérsia sobre distribuição de renda durante o "milagre" brasileiro. Revista de Economia Contemporânea, [s. I.], v. 21, n. 3, p. 1-25, set./dez. 2017. Disponível em:_http://www.scielo.br/ scielo.php?script=sci_abstract\&pid=S1415-98482017000300203\&lng=en\&nrm=iso\&tlng=pt. Acesso em: 03 jul. 2019.

BARROS, Ricardo Paes de; FOGUEL, Miguel Nathan; ULYSSEA, Gabriel (Org.). Desigualdade de renda no Brasil: uma análise da queda recente. Brasília, DF: IPEA, 2007. v.1.

BARROS, Ricardo Paes de; FOGUEL, Miguel Nathan; ULYSSEA, Gabriel (Org.). Desigualdade de renda no Brasil: uma análise da queda recente. Brasília, DF: IPEA, 2008. v.2.

BASTOS, Pedro Paulo. Razões econômicas, não economicistas, do golpe de 1964. Texto para discussão, Campinas, n. 229, p. 1-22, mar. 2014.

BELIK, Walter; BALSADI, Otavio Valentim; BORIN, Maria Rosa; CAPANHOLA, Clayton; DEL GROSSI, Mauro Eduardo; SILVA, José Graziano. O emprego rural nos anos 90. In: PRONI, Marcelo; HENRIQUE, Wilnês (Org.). Trabalho, mercado e sociedade: o Brasil nos anos 90. São Paulo: UNESP, 2003. p. 153-197.

BELLUZZO, Luiz Gonzaga. Apresentação. In: OLIVEIRA, Fabricio Augusto. A reforma tributária de 1966 e a acumulação de capital no Brasil. São Paulo: Brasil Debates, 1981, p. IIV.

BERTOLA, Luís. Latin American inequality in the long run. Revista de Historia Económica, Journal of Iberian and Latin American Economic History, [s. I.], v. 28, n. 2, p. 219-226, 2010.

BIELSCHOWSKY, Ricardo. Pensamento econômico brasileiro: o ciclo ideológico do desenvolvimentismo. 4. ed. Rio de Janeiro: Contraponto, 2000.

BOGLIACINO, Francesco; ROSSI, Máximo. Introducción al número especial "desigualdad”. Cuadernos de Economía, [s. I.], v. 36, n. 72, p. XI-XV, 2017. Disponível em: https://revistas.unal.edu.co/index.php/ceconomia/article/view/68136/62947. Acesso em: 03 jul. 2019. 
BONELLI, Regis; RAMOS, Lauro. Distribuição de renda no Brasil: avaliação das tendências de longo prazo e mudanças na desigualdade desde meados dos anos 70. Revista de Economia Política, São Paulo, v. 13, n. 2 , p. 64-74, abr./jun.1993. Disponível em: http://www.rep.org.br/PDF/50-5.PDF. Acesso em: 03 jul. 2019.

BONICA, Adam; McCARTHY, Nolan; POOLE, Keith T.; ROSENTHAL, Howard. Why hasn't democracy slowed rising inequality? Journal of Economic Perspective, [S. I.], v. 27, n. 3, p. 103-124, Summer 2013.

BRASIL. Código Tributário Nacional. Brasília, DF: [s.n.], 1967.

BRASIL. [Constituição (1988)]. Constituição da República Federativa do Brasil de 1988. Brasília, DF: Presidência da República, 2016. Disponível em:

http://www.planalto.gov.br/ccivil_03/constituicao/constituicao.htm. Acesso em: 3 jul. 2019.

BRASIL. Receita Federal. Ministério da Economia. 1964 a 1967: a reforma tributária. 2015. Disponível em: http://receita.economia.gov.br/sobre/institucional/memoria/imposto-derenda/historia/1964-a-1967-a-reforma-tributaria. Acesso em: 03 jul. 2019.

BRASIL. Receita Federal. Ministério da Economia. Declarações de imposto de renda pessoa física 2016 (DIRPF - 2016). Brasília, DF: [s.n.], 2016. Disponível em: www.receita.fazenda.gov.br. Acesso em: 22 dez. 2018.

BRASIL. Receita Federal. Ministério da Economia. Carga tributária no Brasil 2017. Brasília, DF: [s.n.], Dez. 2018.

BRESSER-PEREIRA, Luiz Carlos. A construção política do Brasil: sociedade, economia e Estado desde a independência. São Paulo: Editora 34 Ltda, 2014.

CACCIAMALI, Maria Cristina. A política de salário mínimo e a sua influência na distribuição de renda. Brasil: Ministério do Trabalho e do Emprego. Abril 2005. Disponível em: http://www.mte.gov.br/sal_min/t03.pdf._Acesso em: 17 jul. 2015.

CACCIAMALI, Maria Cristina; PORTELA, André; FREITAS, Eduardo. O papel do salário mínimo nos anos 80: novas observações para o caso brasileiro. Revista Brasileira de Economia, Rio de Janeiro, v. 48, n. 1, p. 29-45, jan./mar. 1994. Disponível em: http://bibliotecadigital.fgv.br/ojs/index.php/rbe/article/view/598/7943. Acesso em: 03 jul. 2019.

CARNEIRO, Francisco Galrão; FARIA, João Ricardo. Causality between the minimum wage and other wages. Applied Economics Letters, [s.l.], v. 4, p. 507-510, 1997. 
CASTRO, Flávio Ávila. Imposto de Renda Pessoa Física: comparações internacionais, medidas de progressividade e redistribuição. 2014. Dissertação (Mestrado em Economia) Universidade de Brasília (UnB). Brasília, DF, 2014. Disponível em: http://repositorio.unb.br/bitstream/10482/16511/1/2014_F\%C3\%A1bioAvilaDeCastro.pdf. Acesso em: 03 jul. 2019.

COATSWORTH, John H. Inequality, institutions and economic growth in Latin America. Journal of Latin American Studies, [s. I.], v. 40, n. 3, p. 545-569, jul. 2008.

DEDECCA, Cláudio Salvadori. Trabalho, financeirização e desigualdade. Texto para discussão, Campinas, n. 174, p. 1-18, abr. 2010.

DEDECCA, Cláudio Salvadori. Desigualdade, mas de qual falamos? Texto para discussão, Campinas, n. 168, p. 1-32, out. 2009.

DEDECCA, Cláudio Salvadori. A redução da desigualdade no Brasil: uma estratégia complexa. In: BARROS, Ricardo Paes de; FOGUEL, Miguel Nathan; ULYSSEA, Gabriel (Org.).

Desigualdade de renda no Brasil: uma análise da queda recente. Brasília, DF: IPEA, 2007. v.1. p. 299-330.

DEDECCA, Cláudio Salvadori. Anos 90: a estabilidade com desigualdade. In: PRONI, Marcelo; HENRIQUE, Wilnês (Org.). Trabalho, mercado e sociedade: o Brasil nos anos 90. São Paulo: UNESP, 2003. p. 71-106.

DEDECCA, Cláudio Salvadori, JUNGBLUTH, Adriana, TROVÃO, Cassiano José Bezerra. A queda recente da desigualdade: relevância e limites. In: ENCONTRO NACIONAL DA ANPEC, 36., 2008, Salvador. Anais [...]. Salvador: ANPEC, 2008. p. 1-19. Disponível em: http://www.anpec.org.br/encontro2008/artigos/200807211447120-.pdf. Acesso em: 03 jul. 2019.

FONSECA, Pedro Cézar Dutra. Vargas: o capitalismo em construção. São Paulo: Brasiliense, 1987.

FRANKEMA, Ewout H.P. Has Latin America always been unequal? A comparative study of asset and income inequality in the long twentieth century. Leiden/Boston: Brill, 2009.

FURTADO, Celso. Formação econômica do Brasil. São Paulo: Companhia Editora Nacional, 1959.

FURTADO, Celso. O Plano Trienal e o Ministério do Planejamento. Rio de Janeiro:

Contraponto/Centro Internacional Celso Furtado, 2011. (Arquivos Celso Furtado, v. 4). 
HACKER, Jacob S., PIERSON, Paul. Winner-take-all politics: public policy, political organization, and the precipitous rise of top incomes in the United States. Politics \& Society, [s. I.], v. 38, n. 2, p. 152-204, May. 2010. Disponível em:

https://journals.sagepub.com/doi/pdf/10.1177/0032329210365042. Acesso em: 03 jul. 2019.

HICKS, John R. Value and capital. Oxford: Calendron Press, 1939.

HICKS, John R. The valuation of the social income. Economica, London, v. 7, n. 26, May. 1940.

HICKS, John R. The valuation of the social income: a comment on Professor Kuznets' reflections. Economica, London, v. 15, n. 59, Aug. 1948.

IBGE. Séries históricas: carga tributária bruta 1947-2009. [S.I.:s.n.]. Disponível em: www.ibge.gov.br. Acesso em: 10 jul. 2015.

IMF. Tackling Inequality. Fiscal Monitor. October, 2017.

IPEA. Equidade Fiscal no Brasil: Impactos distributivos da tributação e do gasto social.

Comunicados do IPEA, Brasília, DF, n. 92, maio 2011a. Disponível em:

http://repositorio.ipea.gov.br/bitstream/11058/5207/1/Comunicados_n92_Equidade.pdf.

Acesso em: 03 jul. 2019.

IPEA. Gastos com a política social: alavanca para o crescimento com distribuição de renda.

Comunicados do IPEA, Brasília, DF, n. 75, fev. 2011b. Disponível em:

http://www.ipea.gov.br/portal/images/stories/PDFs/comunicado/110203_comunicadoipea75. pdf. Acesso em: 03 jul. 2019.

IPEA. Receita pública: quem paga e como se gasta no Brasil. Comunicado da Presidência, Brasília, DF, n. 22, jun. 2009a. Disponível em:

http://repositorio.ipea.gov.br/bitstream/11058/5297/1/Comunicado_n22_Receita.pdf. Acesso em: 03 jul. 2019.

IPEA. Política fiscal e justiça social no brasil: o caso do IPTU. Comunicado da Presidência, Brasília, DF, n. 29, ago. 2009b. Disponível em:

http://repositorio.ipea.gov.br/bitstream/11058/5314/1/Comunicado_n28_Pol\%c3\%adtica.pdf. Acesso em: 03 jul. 2019.

KERSTENETZKY, Célia Lessa. 0 estado do bem-estar social na idade da razão. Rio de Janeiro: Elsevier, 2012.

KUZNETS, Simon. On the valuation of social income: reflections on Professor Hicks - Part I. Economica, London, v. 15, n. 57, Feb. 1948a. 
KUZNETS, Simon. On the valuation of social income - reflections on Professor Hicks - Part II. Economica, London, v. 15, n. 58, May. 1948b.

LANGONI, Carlos Geraldo. Distribuição de renda e desenvolvimento econômico do Brasil. Rio de Janeiro: Expressão e Cultura, 1973.

LINDERT, Peter H. Toward a comparative history of income and wealth inequality. In: BRENNER, Y. S.; KAELBE, Hartmut; THOMAS, Mark. (Ed.). Income distribution in historical perspective. [S. I.]: Cambridge University Press, 1991, p. 212-231.

LUSTIG, Nora. Fiscal policy and income redistribution in Latin America: challenging the conventional wisdom. Working Paper, Tulane University, n. 1124, Oct. 2011.

LUSTIG, Nora; LOPEZ-CALVA, Luis F.; ORTIZ-JUAREZ, Eduardo. Declining inequality in Latin America in the 2000s: the cases of Argentina, Brazil, and Mexico. World Development, [s.l.], v. 44, p. 129-141, Apr. 2013. Disponível em:

https://www.sciencedirect.com/science/article/pii/S0305750X12002276. Acesso em: 03 jul. 2019.

LUXEMBOURG INCOME STUDIES. [S.I.]. Database. Disponível em:

https://www.lisdatacenter.org/our-data/lis-database. Acesso em: 10 dez. 2018.

MAHON, James. Tax reforms and income distribution in Latin America. In: BLOFIELD, Merike. The great gap: inequality and the politics of redistribution in Latin America. University Park: Pennsylvania State University Press, 2011.

MAHON, James. Tax reforms and income distribution in Latin America. In: CONGRESS OF THE LATIN AMERICAN STUDIES ASSOCIATION, 28., 2009, Rio de Janeiro. Anais [... ]. Rio de Janeiro: LASA, 2009.

MATTOS, Fernando Augusto Mansor. Aspectos históricos e metodológicos da evolução recente do perfil distributivo brasileiro. São Paulo em Perspectiva, São Paulo, v. 19, n. 2, p. 135-149, abr./jun. 2005.

MATTOS, Fernando Augusto Mansor; CARDOSO Jr., José Celso. Novas evidências acerca da questão distributiva no Plano Real. Revista Leituras de Economia Política, Campinas, n. 7, p. 13-27, 1999.

MATTOS, Fernando Augusto Mansor.; BASTOS, Pedro Paulo Zahluth; BARONE, Ricardo. O "debate pioneiro" sobre distribuição de renda no Brasil: como o padrão de acumulação gestado no governo militar de 1964 afetou o perfil distributivo da economia brasileira. In: MARTINS, Mônica de Souza Nunes; CAMPOS, Pedro Henrique Pedreira; BRANDÃO, Rafael 
Vaz da Motta (Org.). Política econômica nos anos de chumbo. Rio de Janeiro: Consequência, 2018. p. 23-53.

MEDEIROS, Marcelo; CASTRO, Fábio Ávila; SOUZA, Pedro Henrique G.F. A estabilidade da desigualdade de renda no Brasil, 2006 a 2012: estimativas com dados do Imposto de Renda e pesquisas domiciliares. Revista Ciência e Saúde Coletiva, Rio de Janeiro, v. 20, n. 4, p. 971986, abr. 2015.

MORGAN, Marc. Falling inequality beneath extreme and persistent concentration: new evidence for Brazil combining national accounts, surveys and fiscal data, 2001-2015. [S. I.]: World Wealth \& Income Database, 2017. (WID.world workig paper). Disponível em: https://wid.world/document/extreme-persistent-inequality-new-evidence-brazil-combiningnational-accounts-surveys-fiscal-data-2001-2015-wid-world-working-paper-201712/. Acesso em: 04 jul. 2019.

ECD. Growing unequal?: Income distribution and poverty in OECD countries. Paris: $O E C D$, 2008.

OLIVEIRA, Fabricio Augusto. A reforma tributária de 1966 e a acumulação de capital no Brasil. São Paulo: Brasil Debates, 1981.

PAEG - Programa de Ação Econômica do Governo 1964-1966. Documentos EPEA. Rio de Janeiro: 1964. n. 1.

PAYERAS, José Adrian P. Análise da progressividade da carga tributária sobre a população brasileira. Pesquisa e Planejamento Econômico (PPE), Brasília, DF: IPEA, p. 153-186, ago. 2010.

PIKETTY, Thomas. A economia da desigualdade. Rio de Janeiro: Intrínseca, 2015.

PIKETTY, Thomas. O capital no século XXI. Rio de Janeiro: Intrínseca, 2014.

POCHMANN, Márcio. Nova classe média?: o trabalho na base da pirâmide social brasileira. São Paulo: Boitempo, 2012.

POCHMANN, Márcio. O trabalho sob fogo cruzado. São Paulo: Contexto, 1999.

RESENDE, André Lara. A política brasileira de estabilização: 1963/68. Pesquisa e Planejamento Econômico, Brasília, DF, v. 12, n. 3, 1982. Disponível em: http://repositorio.ipea.gov.br/handle/11058/6335. Acesso em: 03 jul. 2019.

RESENDE, André Lara. Estabilização e reforma: 1964-1967. In: ABREU, Marcelo de Paiva. A ordem do progresso. Rio de Janeiro: Editora Campus, 1990. p. 197-211. 
SABOIA, João Maurity. Salário mínimo no Brasil: a experiência brasileira. Porto Alegre: L \& $\mathrm{PM}, 1985$.

SANTOS, Lucas Siqueira dos. Reforma tributária no Brasil: histórico, necessidades e propostas. 2015. Dissertação (Mestrado em Direito Tributário) - Escola de Direito de São Paulo da Fundação Getúlio Vargas, São Paulo, 2015. Disponível em:

https://bibliotecadigital.fgv.br/dspace/handle/10438/13965. Acesso em: 03 jul. 2019.

SECCO, Lincoln. História do PT. São Paulo: Ateliê Editorial, 2018.

SINGER, André. Os sentidos do Lulismo: reforma gradual e pacto conservador. São Paulo: Companhia das Letras, 2012.

SINGER, Paul. A crise do “milagre”. Rio de Janeiro: Paz e Terra, 1976.

SINGER, Paul. Repartição da renda: pobres e ricos sob o regime militar. Rio de Janeiro: Jorge Zahar, 1986.

SKIDMORE, Thomas. Brasil: de Getúlio a Castelo (1930 a 1964). 12. ed. Rio de Janeiro: Paz e Terra, 1982.

SOUEN, Jaqueline. A política do salário mínimo no governo Lula. 2013. Dissertação (Mestrado em Economia) - Universidade Estadual de Campinas, Instituto de Economia, Campinas, SP, 2013. Disponível em: http://repositorio.unicamp.br/handle/REPOSIP/286108. Acesso em: 03 jul. 2019.

SOUZA, Paulo Renato. Emprego, salários e pobreza. São Paulo: Hucitec, 1980.

SOUZA, Paulo Renato; BALTAR, Paulo Eduardo de Andrade. Salário mínimo e taxa de salários no Brasil. Pesquisa e Planejamento Econômico, Rio de Janeiro: IPEA, v. 9, n. 3, p. 629-650, dez. de 1979.

SOUZA, Pedro Herculano Guimarães Ferreira de. A desigualdade vista do topo: a concentração de renda entre os ricos no Brasil, 1926-2013. 2016. Tese (Doutorado em Ciências Sociais) - Departamento de Sociologia, Instituto de Ciências Sociais, Universidade de Brasília, Brasília, DF, 2016. Disponível em: http://repositorio.unb.br/handle/10482/22005. Acesso em: 03 jul. 2019.

TAVARES, Maria da Conceição. O sistema financeiro brasileiro e o ciclo de expansão recente. In: BELLUZZO, Luiz Gonzaga; COUTINHO, Renata (Org.). Desenvolvimento capitalista no Brasil. São Paulo: Ed. Brasiliense, 1983. n. 2, p. 107-138. 
UNITED NATIONS. The inequality predicament: report on the world social situation. New York, 2005.

VARSANO, Ricardo. A evolução do sistema tributário brasileiro ao longo do século: anotações e reflexões para futuras reformas. Texto para Discussão, n. 405. Brasília, DF, p. 134, jan. 1996.

ZOCKUN, Maria Helena. Aumenta a regressividade dos impostos no Brasil. Informações FIPE, [São Paulo], n. 297, p.11-13, jun. 2005. Disponível em:

http://downloads.fipe.org.br/content/downloads/publicacoes/bif/2005/6_bif297.pdf. Acesso em: 04 jul. 2019. 